\title{
Impaired Regulation of Thalamic Pacemaker Channels through an Imbalance of Subunit Expression in Absence Epilepsy
}

\author{
Thomas Budde, ${ }^{1 \star}$ Luigi Caputi, ${ }^{3 \star}$ Tatyana Kanyshkova, ${ }^{3 *}$ Rainer Staak, ${ }^{3}$ Christian Abrahamczik, ${ }^{3}$ Thomas Munsch, ${ }^{3}$ \\ and Hans-Christian Pape ${ }^{2}$ \\ ${ }^{1}$ Institut für Experimentelle Epilepsieforschung and ${ }^{2}$ Institut für Physiologie I, Westfälische Wilhelms-Universität Münster, D-48149 Münster, Germany, \\ and ${ }^{3}$ Institut für Physiologie, Otto-von-Guericke-Universität Magdeburg, D-39120 Magdeburg, Germany
}

The role of hyperpolarization-activated, cyclic nucleotide-modulated $(\mathrm{HCN})$ channel isoforms and hyperpolarization-activated cation current $\left(I_{\mathrm{h}}\right)$ for seizure-related burst firing in thalamocortical (TC) neurons was investigated in a rat genetic model of absence epilepsy [Wistar Albino Glaxo rats, bred in Rijswijk (WAG/Rij)]. Burst discharges in TC neurons locked to seizure activity in vivo were prolonged during blockade of $I_{\mathrm{h}}$ by Cs ${ }^{+}$and ZD7288 (4-ethylphenylamino-1,2-dimethyl-6-methylaminopyrimidinium chloride). In vitro analyses revealed a hyperpolarizing shift of half-maximal $I_{\mathrm{h}}$ activation $\left(V_{\mathrm{h}}\right)$ in WAG/Rij $\left(V_{\mathrm{h}}=-93.2 \mathrm{mV}\right)$ compared with nonepileptic controls [August $\times$ Copenhagen-Irish (ACI) $\left(V_{\mathrm{h}}=-88.0 \mathrm{mV}\right)$ ]. This effect is explained by a shift of the responsiveness of $I_{\mathrm{h}}$ to cAMP toward higher concentrations in TC neurons from WAG/Rij, as revealed by application of 8-bromo-cAMP and the phosphodiesterase inhibitor IBMX. During blockade of adenylyl cyclase activity, $I_{\mathrm{h}}$ activation was similar in the two strains, whereas the difference in cAMP responsiveness persisted, thereby voting against different ambient cAMP levels between strains. Increasing the intracellular cAMP level and shifting $I_{\mathrm{h}}$ activation led to a change from burst to tonic firing mode in WAG/Rij but not in ACI rats. Furthermore, HCN1 expression was significantly increased on mRNA and protein levels, with no changes in HCN2 - 4 expression. In conclusion, there is an increase in HCN1 expression in the epileptic thalamus, associated with a decrease in cAMP responsiveness of $I_{\mathrm{h}}$ in TC neurons and resulting impairment to control the shift from burst to tonic firing, which, in turn, will prolong burst activity after recruitment of $I_{\mathrm{h}}$ during absence seizures.

Key words: absence epilepsy; h-current; HCN channels; thalamic dysfunction; spike-and-wave; cAMP

\section{Introduction}

The thalamocortical system is able to generate rhythmic network activity during slow-wave sleep (Steriade et al., 1997). The cellular substrate of these oscillations include the periodic interaction of intrinsic and synaptic membrane currents, to which the hyperpolarization-activated cation current $\left(I_{\mathrm{h}}\right)$ makes an important contribution (Pape, 1996). In thalamocortical (TC) neurons, $I_{\mathrm{h}}$ functions as a pacemaker mechanism during rhythmic burst discharges accompanying $\delta$ sleep (Pape, 1996). Activation and deactivation of $I_{\mathrm{h}}$ have been shown to shape the typical waxing and waning activity characterizing sleep spindles (Lüthi and McCormick, 1998). Furthermore, regulation of the voltage dependence of $I_{\mathrm{h}}$ through the adenylyl cyclase/cAMP system provides one important mechanism for the control of sleep-related burst firing (Pape, 1996; Lüthi and McCormick, 1998). Although it is

Received Jan. 28, 2005; revised Sept. 5, 2005; accepted Sept. 6, 2005.

This work was supported by Deutsche Forschungsgemeinschaft (BU 1019/5-1, MU 1686/1-2, Leibniz-Program to H.-C. P.) and Kultusministerium Sachsen-Anhalt. We thankS. Staak for expert help with the in vivo experiments, A. Reupsch for expert histology, and A. Jahn and R. Ziegler for expert technical assistance.

*T.B., L.C., and T.K. contributed equally to this work.

Correspondence should be addressed to Hans-Christian Pape, Institut für Physiologie I, Westfälische WilhelmsUniversität Münster, Robert-Koch-Strasse 27 a, D-48149 Münster, Germany. E-mail: papechris@ukmuenster.de. DOI:10.1523/JNEUROSCI.2590-05.2005

Copyright $\odot 2005$ Society for Neuroscience $\quad 0270-6474 / 05 / 259871-12 \$ 15.00 / 0$ known that thalamocortical mechanisms and networks that generate oscillatory activity during sleep are critically involved also in the pathological transformation toward spike-wave discharges (SWDs) characterizing absence seizures during petit mal epilepsy (McCormick and Bal, 1997; Crunelli and Leresche, 2002), the role of $I_{\mathrm{h}}$ has remained elusive.

Views on $I_{\mathrm{h}}$ have evolved along two important lines. (1) Four members of a gene family encoding mammalian hyperpolarization-activated, cyclic nucleotide-gated cation channels (HCN1-4) have been cloned (Kaupp and Seifert, 2001; Santoro and Baram, 2003). Four subunits are thought to assemble to form homomeric or heteromeric functional channels, of which the kinetics, voltage dependency, and cAMP sensitivity are primarily determined by the particular subunit composition. For instance, compared with $\mathrm{HCN} 2$, the $\mathrm{HCN} 1$ isoform confers faster activation kinetics, a more depolarized membrane voltage of activation, and very little response to direct cAMP-dependent modulation. Furthermore, the expression pattern of $\mathrm{HCN}$ isoforms in the mammalian brain displays regional and species differences (Moosmang et al., 1999) and is developmentally regulated (Bender et al., 2001). (2) Evidence has been obtained recently for an effect of neuronal activity on $I_{\mathrm{h}}$ channel expression and function, with particular relationship to epileptic activity. Seizures resulted in altered electrophysiological properties of $I_{\mathrm{h}}$ and influ- 
enced the ratio of HCN1 and HCN2 expression in different cell types of the hippocampus and entorhinal cortex (K. Chen et al., 2001; Brewster et al., 2002; Bender et al., 2003; Shah et al., 2004). In addition, the genetic knock-out of the HCN2 isoform resulted in altered $I_{\mathrm{h}}$ in TC neurons and absence of seizure-like activity (Ludwig et al., 2003), and a reduced HCN1 protein expression has been found in the neocortex of a rat genetic absence epilepsy model (Strauss et al., 2004). These results suggested the differential regulation of $\mathrm{HCN}$ isoforms in neuropathological conditions and prompted HCN subunits to be proposed as candidates for antiepileptic strategies (Chen et al., 2002), although a causal relationship between the expression of $\mathrm{HCN}$ isoforms, $I_{\mathrm{h}}$ function, and spontaneous seizures in chronic epilepsy had not been obtained from these studies. Therefore, we have undertaken the present study to analyze the possible contribution of HCN channels to the evolution of SWD using a rat genetic model of absence epilepsy (WAG/Rij) (Renier and Coenen, 2000), combined with electrophysiological and molecular biological techniques.

\section{Materials and Methods \\ Electrophysiology in vivo}

Operative procedures. Experiments in rats of the WAG/Rij strain in vivo were performed as described previously (Seidenbecher et al., 1998; Staak and Pape, 2001) and were approved by the Regierungspräsidium Dessau (AZ 53a-42502/2-028/5). Data are from a total of $30 \mathrm{WAG} / \mathrm{Rij}$ (aged 130-307 d; weight, $356 \pm 5 \mathrm{~g}$ ). Operative procedures were performed under deep pentobarbital anesthesia $(40-60 \mathrm{mg} / \mathrm{kg}$, i.p), with Xylocaine cream (ASTRA GmbH, Wedel, Germany) applied to wound and pressure points. Animals were fixed in a stereotaxic frame (David Kopf Instruments, Tujunga, CA) with bregma and lambda in a horizontal plane. The epidural EEG was monitored bilaterally [anteroposterior (AP), +2.0 $\mathrm{mm}$; mediolateral (ML), $3.6 \mathrm{~mm}$ from bregma], and body temperature was kept at $36-38^{\circ} \mathrm{C}$. Recordings were performed under neurolept anesthesia $\left[0.079 \pm 0.003 \mathrm{mg} \cdot \mathrm{kg}^{-1} \cdot \mathrm{h}^{-1}\right.$ fentanyl (Janssen-Cilag, Neuss, Germany or CuraMed, Karlsruhe, Germany) and $6.67 \pm 0.27$ $\mathrm{mg} \cdot \mathrm{kg}^{-1} \cdot \mathrm{h}^{-1}$ droperidol (Sigma, St. Louis, MO)]. In some animals, recordings were obtained under pentobarbital anesthesia $(n=5 ; 24.0 \pm$ $1.5 \mathrm{mg} \cdot \mathrm{kg}^{-1} \cdot \mathrm{h}^{-1}$ pentobarbital; Sigma) or deep neurolept anesthesia $\left(0.107 \pm 0.006 \mathrm{mg} \cdot \mathrm{kg}^{-1} \cdot \mathrm{h}^{-1}\right.$ fentanyl, $n=5 ; 8.25 \pm 0.28$ $\mathrm{mg} \cdot \mathrm{kg}^{-1} \cdot \mathrm{h}^{-1}$ droperidol, $\left.n=5\right)$. The level of anesthesia and analgesia was monitored through the EEG and limb withdrawal in response to tactile stimuli. At signs of insufficient anesthesia, fentanyl and droperidol were additionally applied intraperitoneally.

Microiontophoretic and recording techniques in vivo. Five-barrel (Hilgenberg, Malsfeld, Germany) glass microelectrodes were used for extracellular unit recording and microiontophoresis. The recording barrel was filled with $0.6 \mathrm{M}$ sodium acetate and connected to an amplifier (highpass and low-pass filters set at 0.5 and $10 \mathrm{kHz}$, respectively; EXT-20F; npi Electronic GmbH, Tamm, Germany). One barrel filled with $0.6 \mathrm{~m}$ sodium-acetate and 2-6\% Chicago sky blue was used for current balancing and for labeling the recording site. The remaining barrels contained $\mathrm{CsCl}$ (Sigma, Taufkirchen, Germany) (150 mm, pH 3.4-3.55) or 4-ethylphenylamino-1,2-dimethyl-6-methylaminopyrimidinium chloride (ZD7288; 0.2 or $2 \mathrm{~mm}$ in $0.9 \% \mathrm{NaCl}$, pH 3.4-3.55; Biotrend, Cologne, Germany). Microiontophoresis was controlled with a NeuroPhore-BH-2 (Medical Systems, Greenvale, NY). Impedance of the electrodes (at $1 \mathrm{kHz}$ ) was $10-20 \mathrm{M} \Omega$; ejection and retaining currents were +3 to $+30 \mathrm{nA}$ and $-10 \mathrm{nA}$, respectively. Electrodes were lowered into the ventrobasal complex (VB) (coordinates in $\mathrm{mm}$ from bregma: AP, -3.0; ML, 3.3; depth, 5.45-6.0) using a micropositioner (model 650; David Kopf Instruments). Analog data were fed into a computer via an analog-to-digital interface (1401plus; Cambridge Electronic Design, Cambridge, UK) and analyzed using the Spike-2 software (Cambridge Electronic Design). Unit activity was discriminated from noise using a level-time function of Spike-2.

Histological procedures. Animals were killed by an overdose of pentobarbital (150 mg/kg, i.p.), the brains were fixed with $4 \%$ phosphate- buffered paraformaldehyde, $\mathrm{pH} 7.4$, and immersed in 30\% sucrose. Chicago sky blue injections were identified in frozen frontal sections (40 $\mu \mathrm{m}$ ) counterstained with cresyl violet. Only data from recordings with histologically verified recording sites were included in the analysis.

\section{Electrophysiology in vitro}

Preparation of slices. In the present study, the WAG/Rij model was compared with rats of the August $\times$ Copenhagen-Irish (ACI) strain, the only inbred rat strain free of spike-wave activity (Coenen and Van Luijtelaar, 2003). ACI $(n=81)$ and WAG/Rij $(n=65)$ rats of either sex [postnatal day 16 (P16) to P29] were anesthetized with halothane and decapitated. A block of tissue containing the thalamus was removed and placed in ice-cold saline, containing the following (in mM): 200 sucrose, 20 PIPES, $2.5 \mathrm{KCl}, 1.25 \mathrm{NaH}_{2} \mathrm{PO}_{4}, 10 \mathrm{MgSO}_{4}, 0.5 \mathrm{CaCl}_{2}$, and 10 dextrose, pH 7.35 with $\mathrm{NaOH}$. Thalamic slices were prepared as coronal sections on a vibratome. Before recording, slices were kept submerged in standard artificial CSF containing the following (in $\mathrm{mM}$ ): $125 \mathrm{NaCl}, 2.5 \mathrm{KCl}, 1.25$ $\mathrm{NaH}_{2} \mathrm{PO}_{4}, 24 \mathrm{NaHCO}_{3}, 2 \mathrm{MgSO}_{4}, 2 \mathrm{CaCl}_{2}$, and 10 dextrose, $\mathrm{pH}$ adjusted to 7.35 by bubbling with a mixture of $95 \% \mathrm{O}_{2}$ and $5 \% \mathrm{CO}_{2}$.

Whole-cell patch clamp. Recordings were performed on TC neurons of the dorsal lateral geniculate nucleus (dLGN) and VB at room temperature. Slices were recorded in a solution containing the following (in $\mathrm{mM}$ ): $125 \mathrm{NaCl}, 3 \mathrm{KCl}, 1.25 \mathrm{NaH}_{2} \mathrm{PO}_{4}, 22 \mathrm{NaH}_{2} \mathrm{PO}_{4}, 2 \mathrm{MgSO}_{4}, 2 \mathrm{CaCl}_{2}$, and 10 dextrose, pH 7.35 adjusted by bubbling with $95 \% \mathrm{O}_{2} / 5 \% \mathrm{CO}_{2}$. Individual cells were visually identified by infrared differential interference contrast video microscopy (Dodt and Zieglgänsberger, 1990). Membrane currents were measured with pipettes pulled from borosilicate glass (GC150T-10; Clark Electromedical Instruments, Pangbourne, UK), connected to an EPC-10 amplifier (HEKA Elektronik, Lamprecht, Germany), and filled with the following (in $\mathrm{mM}$ ): $95 \mathrm{~K}$-gluconate, $20 \mathrm{~K}_{3}$ citrate, $10 \mathrm{NaCl}, 10$ HEPES, $1 \mathrm{MgCl}_{2}, 0.5 \mathrm{Ca} \mathrm{Cl}_{2}, 3$ BAPTA, $3 \mathrm{Mg}$-ATP, and $0.5 \mathrm{Na}-\mathrm{GTP}$. The internal solution was set to a $\mathrm{pH}$ of 7.25 with $\mathrm{KOH}$ and an osmolarity of $295 \mathrm{mOsm} / \mathrm{kg}$. Typical electrode resistance was 2-3 $\mathrm{M} \Omega$, with an access resistance in the range of 5-15 M $\Omega$. Series resistance compensation of $>40 \%$ was routinely used. Electrophysiological experiments were governed by Pulse software (HEKA Elektronik) operating on an IBM-compatible computer. A liquid junction potential of $10 \pm 1$ $\mathrm{mV}(n=6)$ was measured and taken into account (Neher, 1992). Resting potential was determined as zero current potential under current-clamp conditions. Thereafter, input resistance was determined by applying small (5-10 pA) depolarizing and hyperpolarizing current steps and dividing the resulting voltage deflection by the applied current.

\section{Experimental protocol and data analysis}

Peri-event time (PT) histograms of unit activity were constructed using the maximum peak of the spike component of a given SWD on the EEG as a trigger (EEG-triggered analysis) (Staak and Pape, 2001). The counts were calculated in $3 \mathrm{~ms}$ bins in a time range $39 \mathrm{~ms}$ before and $6 \mathrm{~ms}$ after the spike peak on the EEG (spike-locked activity) and 15-60 ms after the spike peak on the EEG (wave-locked activity) (see Fig. $1 \mathrm{~B}$ ). This temporal range seemed feasible, because spike-locked burst firing in various brain regions of WAG/Rij or genetic absence epilepsy rats from Strasbourg (GAERS), including thalamocortical relay nuclei, the reticular thalamic nucleus, and the somatosensory cortex, peaks $\sim 20-5 \mathrm{~ms}$ before the peak of the EEG spike and sharply declines within $5 \mathrm{~ms}$ after the EEG spike peak (Inoue et al., 1993; Seidenbecher et al., 1998; Staak and Pape, 2001). Activity in intralaminar nuclei, by comparison, sharply peaks at $\sim 10 \mathrm{~ms}$ after the spike peak on the EEG and is considered wave-locked (Seidenbecher and Pape, 2001). An overall duration of the time window of $105 \mathrm{~ms}$ was used in view of the mean frequency of occurrence of SWD at 7-10 Hz. The average number of discharges per each SWD was calculated from the number of spikes in PT histograms divided by the respective number of SWD. For evaluation of $\mathrm{Cs}^{+}$or ZD7288 effects, SWD were monitored within intervals of $40 \mathrm{~s}$ duration. When no change in SWD frequency was observed (control period), application of a drug commenced, and the effect on SWD-related activity was monitored in intervals of $40 \mathrm{~s}$ duration every $2 \mathrm{~min}$, followed by cessation of drug application (recovery period). The number of unit discharges per SWD was calculated from these intervals. Data from different unit recordings 
were averaged using this protocol. In addition, the effects of $\mathrm{Cs}^{+}$and ZD7288 on burst activity were monitored in rats displaying no SWD in intervals of $30 \mathrm{~s}$ over a time period of $6 \mathrm{~min}$ (two control intervals of $30 \mathrm{~s}$ duration with no drug application preceded each drug application). Patterns of unit activity were considered as a burst when a minimum of two initial spikes occurred at a frequency exceeding $300 \mathrm{~Hz}$, and subsequent spikes occurred at frequencies exceeding $125 \mathrm{~Hz}$ (as specified by the Spike-2 software). Mean burst length was calculated for each interval and averaged from different experiments. One drug was applied only once during a single penetration.

$I_{\mathrm{h}}$ was activated using hyperpolarizing voltage steps from a holding potential of $-50 \mathrm{mV}(-40 \mathrm{mV}$ in some experiments) to $-130 \mathrm{mV}$ $(-120 \mathrm{mV}$ in some experiments) in $10 \mathrm{mV}$ increments. To increase stability of whole-cell recordings, the pulse length was decreased by 500 $\mathrm{ms}$ with increasing depth of the hyperpolarization ( $1.5 \mathrm{~s}$ pulse length at $-130 \mathrm{mV}$ ). In subset of cells protocols eliciting long hyperpolarizations ranging from $15.5 \mathrm{~s}$ at $-50 \mathrm{mV}$ to $3.5 \mathrm{~s}$ at $-130 \mathrm{mV}$ (1.5 s decrement) were used for comparison. Steady-state activation of $I_{\mathrm{h}}, p(\mathrm{O})$, was estimated by normalizing the tail current amplitudes $(I), 50 \mathrm{~ms}$ after stepping to a constant potential from a variable amplitude step using the following equation: $p(\mathrm{O})=\left(I-I_{\min }\right) /\left(I_{\max }-I_{\min }\right)$, with $I_{\max }$ being the tail current amplitude for the voltage step from $-130 \mathrm{mV}$ (in some experiments $-120 \mathrm{mV})$ to $-80 \mathrm{mV}(-90 \mathrm{mV}$ in some experiments) and $I_{\min }$ for the voltage step from $-40 \mathrm{mV}$ (in some experiments $-50 \mathrm{mV}$ ) to $-80 \mathrm{mV}$ ( $-90 \mathrm{mV}$ in some experiments), respectively. $I_{\mathrm{h}}$ activation was usually well accounted for a Boltzmann distribution of the following form: $p(\mathrm{O})=1 /\left(1+\exp \left(\left(V-V_{\mathrm{h}}\right) / k\right)\right)$, where $V_{\mathrm{h}}$ is the voltage of half-maximal activation and $k$ the slope factor.

The fully activated current versus voltage relationship was obtained from instantaneous tail currents. $I_{\mathrm{h}}$ was evoked by a hyperpolarizing step to $-120 \mathrm{mV}$ from a holding potential of $-50 \mathrm{mV}$. The poststep test potential was varied between -110 and $-60 \mathrm{mV}$ in $10 \mathrm{mV}$ increments. The tail current amplitude was plotted against the test pulse potential, fitted using a linear regression, and fully activated conductance and reversal potential were taken from slope and zero-crossing, respectively.

The density of $I_{\mathrm{h}}$ was determined from 20 randomly chosen cells and calculated by dividing the $I_{\mathrm{h}}$ current amplitude at $-120 \mathrm{mV}$ by the membrane capacitance obtained during whole-cell recordings.

The time course of $I_{\mathrm{h}}$ activation in TC neurons in several species is best approximated by a single-exponential function (Pape, 1996), a finding that is corroborated by the present study. The following equation was used: $I_{\mathrm{h}}(t)=A_{\mathrm{o}}+A_{1} \times \mathrm{e}^{-t / \tau}$, where $I_{\mathrm{h}}(t)$ is the amplitude of the current at time $t$, and $A_{0} / A_{1}$ and $\tau$ are amplitude coefficients and the time constant, respectively.

During experiments with 8-bromo-cAMP added to the recording pipette, properties of $I_{\mathrm{h}}$ were determined after a steady state of cAMP action had been reached, as indicated by constant $I_{\mathrm{h}}$ activation kinetics and $I_{\mathrm{h}}$ amplitude at a given hyperpolarizing voltage step $(\sim 5 \mathrm{~min}$ after obtaining the whole-cell configuration). Data were included for analysis when a stable $V_{\mathrm{h}}$ value was obtained in three or more consecutive activation protocols.

All results were presented as mean \pm SEM. Statistical analysis was performed using the two-tailed nonparametric Wilcoxon pair test or the Mann-Whitney $U$ test, as applicable. Differences of $p<0.05$ were considered statistically significant.

\section{Drugs}

ZD7288, CsCl, and 8-bromo-cAMP (Sigma) were prepared as stock solutions in water and dissolved directly in the external and internal recording solution, respectively. IBMX and 9-(tetrahydro-2-furanyl)-9Hpurin-6-amine (SQ22.536) were obtained from Sigma and prepared as stock solutions in DMSO. The final solvent concentration did not exceed $1 \%$. At this concentration, DMSO had no effect on the investigated ion currents. 8-Bromo-cAMP was applied in two different ways: (1) To follow the effect over time, 8-bromo-cAMP was added in a concentration of $1 \mathrm{~mm}$ to the extracellular medium (experiments shown in Figs. 3, 5, and 6). (2) To construct a dose-response curve of the 8-bromo-cAMP effect (experiments shown in Fig. 4), we added defined concentrations to the pipette solution.

\section{Molecular biological and biochemical experiments}

In situ hybridization. WAG/Rij and ACI rats ( $21 \mathrm{~d}$ of age) were anesthetized deeply using halothan. Brains were removed and frozen in $-50^{\circ} \mathrm{C}$ isopentane. Cryostat coronal sections of $16 \mu \mathrm{m}$ thickness were cut at the level of the dLGN, thaw-mounted onto silane-coated slide glasses, and air dried. Digoxigenin-labeled antisense and sense riboprobes were generated by in vitro transcription from vectors containing cDNA of rat $\mathrm{HCN} 1$ (corresponding to base pairs 2562-2787), HCN2 (base pairs 1879-2143), and HCN4 (base pairs 2938-3221). In situ hybridization was performed as described previously (Meuth et al., 2003). In brief, sections were fixed in $4 \%$ paraformaldehyde, washed three times in PBS for $5 \mathrm{~min}$ followed by acetylation, and then prehybridized for $2 \mathrm{~h}$ at $55^{\circ} \mathrm{C}$. The prehybridization solution consisted of $50 \%$ formamide, $5 \times$ SSC, $1 \times$ Denhardt's solution, $0.5 \mathrm{mg} / \mathrm{ml}$ yeast tRNA, and $1.0 \mathrm{mg} / \mathrm{ml}$ total yeast RNA. For hybridization, sections were exposed in $50 \%$ formamide, $1 \times$ Denhardt's solution, $0.1 \mathrm{mg} / \mathrm{ml}$ yeast tRNA, $0.1 \mathrm{mg} / \mathrm{ml}$ total yeast RNA, $10 \%$ dextran sulfate, $0.125 \%$ SDS, 10 mM Tris-HCl, pH 7.5, 1 mm EDTA, and $300 \mathrm{~mm} \mathrm{NaCl}$. Digoxigenin-labeled RNA probes were added (with a final concentration of $50 \mathrm{pg} / \mathrm{ml}$ prehybridization buffer), and sections were incubated at $55^{\circ} \mathrm{C}$ for $16-18 \mathrm{~h}$. For all steps, RNase-free solutions were used. After hybridization, sections were subjected to washes of increasing stringency including $2 \times$ SSC at room temperature (once for 2 min), $50 \%$ formamide $2 \times \mathrm{SSC}$ at $60^{\circ} \mathrm{C}$ (twice for $60 \mathrm{~min}$ ), $2 \times 50 \%$ formamide $/ 0.2 \times \mathrm{SSC}$ at $60^{\circ} \mathrm{C}$ (twice for $90 \mathrm{~min}$ ), and $0.1 \times$ SSC at $60^{\circ} \mathrm{C}$ (once for $90 \mathrm{~min}$ ). Labeled cells were detected with an anti-digoxigenin antibody tagged with alkaline phosphatase (1:500; Roche, Mannheim, Germany). Staining was performed using 4-nitro blue tetrazolium chloride and 5-bromo-4-chloro-3-indolyl phosphate as substrates (Roche).

Specificity of the hybridization reaction was verified by substituting labeled sense probes for the antisense probes. No labeling was observed under these conditions.

In situ hybridization combined with immunocytochemistry. For double labeling, fresh-frozen sections were processed first for in situ hybridization for HCN1 (except an acetylation step). After hybridization and washing, sections were treated with Proteinase $\mathrm{K}(1 \mu \mathrm{g} / \mathrm{ml})$ for $30 \mathrm{~min}$, then subjected to $0.3 \% \mathrm{H}_{2} \mathrm{O}_{2}$ for $30 \mathrm{~min}$ and intensively washed. A rabbit polyclonal antibody to parvalbumin (1:1000; SWANT, Bellinzona, Switzerland) was added together with an anti-digoxigenin antibody in $2 \%$ normal goat serum, $2 \%$ BSA, $0.3 \%$ Triton X-100 in TBS. The antiparvalbumine antibody was detected using a biotinylated anti-rabbit antibody (1:200; Vector Laboratories, Burlingame, CA) after in situ detection. For immunohistochemical visualization, an avidin-biotin-peroxidase system (ABC-Kit; Vector Laboratories) with 3,3'-diaminobenzidine as chromogen $\left(0.02 \%\right.$ solution in $\left.0.005 \% \mathrm{H}_{2} \mathrm{O}_{2}\right)$ was used.

Reverse transcription-PCR assays. Poly(A) mRNA was prepared from freshly dissected tissue by extraction with Trizol reagent according to the manufacturer's instructions (Oligotex; Qiagen, Hilden, Germany). Firststrand cDNA was primed with oligo(dT) from $0.5-1 \mu \mathrm{g}$ of mRNA and synthesized using the SuperScript II enzyme (Invitrogen, San Diego, CA) at $42^{\circ} \mathrm{C}$ for $50 \mathrm{~min}$. PCR amplification was performed in $30 \mu \mathrm{l}$ of reaction mixture containing 0.75 U Taq polymerase (Qiagen), $1.5 \mathrm{~mm} \mathrm{MgCl}_{2}, 0.2$ $\mathrm{mm}$ of each dNTP, and 50 pmol of each primer with following cycling protocol: $3 \mathrm{~min}$ at $94^{\circ} \mathrm{C}$, then 35 cycles of $94^{\circ} \mathrm{C}$ for $30 \mathrm{~s}, 58^{\circ} \mathrm{C}$ for $1 \mathrm{~min}$, $72^{\circ} \mathrm{C}$ for $1 \mathrm{~min}$, with a final elongation of $7 \mathrm{~min}$ at $72^{\circ} \mathrm{C}$. The following intron spanning primer pairs were used: $\beta$-actin (nucleotides 253-1080; GenBank accession number NM_031144), forward, ATT TGG CAC CAC ACT TTC TAC AAT, reverse, CTG CTT GCT GAT CCA CAT CTG C; glyceraldehyde-3-phosphate dehydrogenase (G3PDH; nucleotides 561-1012; GenBank accession number AB017801), forward, ACC ACA GTC CAT GCC ATC AC, reverse, TCC ACC ACC CTG TTG CTG TA; HCN1 (nucleotides 1462-1750; GenBank accession number AF247450), forward, CTC TCT TTG CTA ACG CGG AT, reverse, TTG AAA TTG TCC ACC GAA; HCN2 (nucleotides 1059-1428; GenBank accession number AF247451), forward, GTG GAG CGA ACT CTA TTC GT, reverse, GTT CAC AAT CTC CTC ACG CA; HCN3 (nucleotides 17131945; GenBank accession number AF247452), forward, GCA GCA TTT 
GGT ACA ACA CG, reverse, AGC GTC TAG CAG ATC GAG C; and HCN4 (nucleotides 1871-2042; GenBank accession number AF247453), forward, GCA GCG CAT CCA CGA CTA C, reverse, CGT CAC AAA GTT GGG GTC TGC.

Semiquantitative reverse transcription-PCR. The optimal number of cycles required for the detection of products in the linear range of amplification was determined for each combination of cDNA-primer pairs. The levels of mRNAs from both ACI and WAG/Rij rat tissues were normalized to each other using the constitutively expressed housekeeping genes $\mathrm{G} 3 \mathrm{PDH}$ and $\beta$-actin. Serial dilutions prepared from cDNA samples of WAR/Rij and ACI rats were used for comparative quantification of the $\mathrm{HCN}$ isoforms. Furthermore, each round of analysis included the coamplification of housekeeping genes to control the ratio of amplified cDNAs more precisely. Quantification of each gene is achieved by the densitometric analysis of PCR products followed by calculation of the expression difference determined as a ratio of the PCR product of the WAG/Rij gene to the PCR product of the ACI gene. Each target gene was amplified a minimum of three separate times.

Quantitative real-time PCR. The hybridization primer/probe assays for real-time PCR detection were purchased as assays-on-demand from Applied Biosystems (Foster City, CA). Real-time PCR was performed using the TaqMan universal PCR master mix (Applied Biosystems) and the ABI Prism 7000 sequence detection system (Applied Biosystems). The PCR program was the following: $2 \mathrm{~min}$ at $50^{\circ} \mathrm{C}, 10$ min at $95^{\circ} \mathrm{C}, 50$ cycles of $15 \mathrm{~s}$ at $95^{\circ} \mathrm{C}$ and $1 \mathrm{~min}$ at $60^{\circ} \mathrm{C}$. Results were analyzed with the ABI Prism 7000 SDS software. The efficiency of realtime primer/probes was nearly identical. Quantification was done using the comparative $C_{\mathrm{T}}$ or $\Delta \Delta C_{\mathrm{T}}$ method as described in the ABI User Bulletin \#2 (Applied Biosystems). Hybridization primer/probe assays for real-time PCR detection were purchased from Applied Biosystems (HCN1, Rn00584498_m1; HCN2, Rn01408575_gH; HCN3, Rn00586666_m1; HCN4, Rn00572232_m1; $\beta 2$-microglobulin, Rn00560865_m1). Hybridization primer/ probe assays for real-time PCR detection were purchased from Applied Biosystems (HCN1, Rn00584498_m1, exon boundary, 2/3; HCN2, Rn01408575_gH, exon boundary, 6/7; HCN3, Rn00586666_m1, exon boundary, 6/7; HCN4, Rn00572232_m1, exon boundary, 6/7; $\beta 2$ microglobulin, Rn00560865_m1).

Western blot. Protein samples were separated by $10 \%$ SDS-PAGE and electroblotted onto nitrocellulose membrane. Blots were blocked and incubated with the primary antibody (HCN1, rat polyclonal IgG, 1:400, Alomone Labs, Jerusalem, Israel; $\beta$-actin, mouse monoclonal IgG1, 1:2000, Abcam, Cambridge, MA) for $2 \mathrm{~h}$ and room temperature. Primary antibodies were then detected using peroxidase-conjugated anti-rat and anti-mouse Igs (1:2000 for each antibody; DakoCytomation, High Wycombe, UK) followed by visualization (ECL plus Western blotting detection system; Amersham Biosciences, Braunschweig, Germany). Quantification of comparative HCN1 expression is achieved by the densitometric analysis of protein bands followed by calculation of the expression difference determined as a ratio of the normalized expression of WAG/Rij HCN1 to the normalized ACI HCN1 expression.

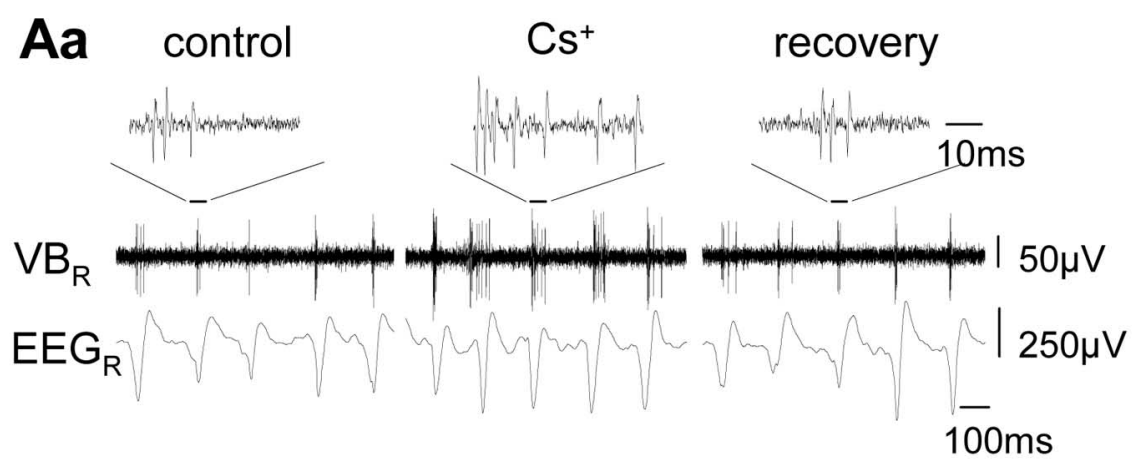

$\mathrm{Ba}$

$\mathrm{Ca}$
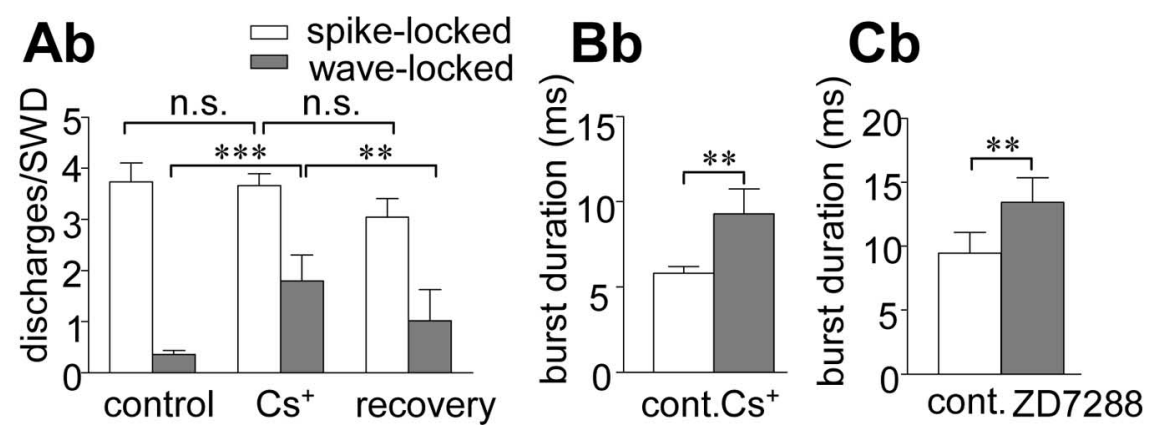

Figure 1. Effect of $/ \mathrm{h}$ blockade on unit discharges in the VB in WAG/Rij in vivo. $A$, Effect of microiontohoretic application of $\mathrm{Cs}^{+}$ uring, and after (recovery) microiontophoretic application of cesium $\left(\mathrm{Cs}^{+}\right)$. Note the spike-locked burst firing of the VB unit and prolion of burst firing during action of $\mathrm{Cs}^{+}$. A $\boldsymbol{b}$, Histograms of spike-locked (open bars) and wave-locked (filled bars) unit discharges per SWD on the EEG before (control), during, and after (recovery) application of $\mathrm{Cs}^{+}$. Data are averaged from recordings of $12 \mathrm{VB}$ units. $\boldsymbol{B}$, Effect of $\mathrm{Cs}^{+}$on burst firing in a VB unit during pentobarbital anesthesia $(\boldsymbol{B a})$ and averaged data from nine $\mathrm{VB}$ deep neurolept $(\boldsymbol{C} \boldsymbol{a})$ and averaged data from $10 \mathrm{VB}$ units $(\boldsymbol{C} \boldsymbol{b})$ showing burst duration before (control) and during action of ZD7288. ${ }^{* *} p<0.01 ;{ }^{* *} p<0.0005$. n.s., Not significant; cont., control; R, right. Error bars represent SEM.

\section{Results}

Effect of $I_{\mathrm{h}}$ current blockers on SWD-related thalamic activity in vivo

In a first experimental step, we evaluated the possible involvement of $I_{\mathrm{h}}$ during SWD-related activity in thalamic neurons of the VB during spontaneous absence seizures in WAG/Rij in vivo. The VB was chosen because it contains mostly TC neurons in the rat, and SWD-related activity is well documented (Renier and Coenen, 2000). All rats of the WAG/Rij strain investigated under standard neurolept anesthesia in the present study $(n=20)$ spontaneously developed bilaterally synchronized SWD at $\sim 5 \mathrm{~Hz}$ on the epidural EEG, which started and ended on a normal background pattern (Inoue et al., 1993, 1994). Unit activity in the VB during SWD was similar to that described previously (Inoue et al., 1993, 1994; Seidenbecher et al., 1998; Staak and Pape, 2001) in that synchronized burst firing occurred with the SWD compo- 
nent on the EEG (Fig. 1A). EEG spike-triggered analysis revealed the phase-locking of unit activity in the VB with the spike component on the EEG (Fig. 1A). Microiontophoretic application of the $I_{\mathrm{h}}$ blocker cesium $\left(\mathrm{Cs}^{+}\right)$resulted in a prolongation of seizurerelated single-unit burst firing in the $\mathrm{VB}$, thereby increasing unit activity correlated with the wave component on the EEG from an average of $0.36 \pm 0.07$ discharges per SWD under control conditions to $1.80 \pm 0.51(n=12)$ (Fig. $1 A)$. Spike-locked unit activity was not affected by $\mathrm{Cs}^{+}(3.74 \pm 0.37$ vs $3.66 \pm 0.24 ; n=12)$. Recovery was obtained within 2-10 min after cessation of drug application (Fig. 1A). Microiontophoretic application of the $I_{\mathrm{h}}$ blocker ZD7288 at $0.2 \mathrm{~mm}$ ( $n=7$; data not shown) significantly enhanced wave-locked activity (from $0.16 \pm 0.04$ to $0.71 \pm 0.12$ discharges per SWD) and did not influence spike-locked activity $(3.06 \pm 0.30$ vs $3.12 \pm 0.40 ; n=7)$, thereby resembling the effect of $\mathrm{Cs}^{+}$. Furthermore, ZD7288 resulted in an overall depression of activity in the VB, as indicated by an increase in the percentage of SWD on the EEG that were not accompanied by burst firing in the VB (from $5.2 \pm 2.1 \%$ under control conditions to $36.3 \pm 9.9 \%$ during ZD7288; $p<2 \times 10^{-2}$ ). Effects of local application of $\mathrm{Cs}^{+}$or ZD7288 on the SWD components on the EEG were not observed. At higher concentrations (2 $\mathrm{mm}$ ), ZD7288 strongly blocked SWD-locked burst firing in the VB. In remaining bursts, both the spike-locked and the wave-locked discharges were significantly $\left(p<5 \times 10^{-4}\right)$ reduced during action of ZD7288 compared with control conditions (spike-locked, $4.23 \pm 0.44-2.08 \pm 0.39$ discharges per SWD; wave-locked, $0.72 \pm 0.16-0.33 \pm 0.06 ; n=12$; data not shown). A comparable depressant effect was not observed during application of $\mathrm{Cs}^{+}$, and therefore it seems reasonable to conclude that the depressant effect of ZD7288 observed in the present study reflects the inhibitory influence on glutamatergic synaptic transmission (Chevaleyre and Castillo, 2002) or low-threshold $\mathrm{Ca}^{2+}$ channels (Felix et al., 2003). Under pentobarbital or deep neurolept anesthesia (see Materials and Methods), SWDs were primarily suppressed, and unit activity in the VB was dominated by randomized burst discharges. Microiontophoretic application of $\mathrm{Cs}^{+}(n=9)$ and ZD7288 (0.2 mM; $n=10)$ under these conditions significantly increased the duration of burst discharges by an average of $57.6 \pm$ $17.6 \%\left(p<1 \times 10^{-2}\right)$ and $45.8 \pm 7.3 \%\left(p<1 \times 10^{-2}\right)$, respectively (Fig. $1 B, C$ ). These data indicated that $I_{\mathrm{h}}$ contributes to burst discharges in VB TC neurons of WAG/Rij, both during seizure-related SWD and during seizure-free states, and, more specifically, that a reduction of $I_{\mathrm{h}}$ results in a prolongation of SWD-related burst firing.

\section{$I_{\mathrm{h}}$ properties in TC neurons of epileptic and a nonepileptic rat strains}

Next, we used in vitro slice preparations to investigate the basic properties of $I_{\mathrm{h}}$ in TC neurons in VB and the dLGN of epileptic WAG/Rij and compared them with those of the specific nonepileptic ACI strain and control strains with lesser or undetermined epileptic susceptibility (Wistar, Long-Evans). A series of hyperpolarizing voltage steps (ranging from $15.5 \mathrm{~s}$ at $-50 \mathrm{mV}$ to $3.5 \mathrm{~s}$ at $-130 \mathrm{mV}$ ) elicited a slow inward current exhibiting typical $I_{\mathrm{h}^{-}}$ like characteristics in dLGN TC neurons of ACI (Fig. $2 A$, left) and WAG/Rij (Fig. $2 A$, right). The construction of steady-state activation curves from tail currents in animals older than P15 revealed that the $V_{\mathrm{h}}$ in ACI rats $\left(V_{\mathrm{h}}=-85.3 \pm 2.1 \mathrm{mV} ; n=16\right)$ was significantly $\left(p<2 \times 10^{-2}\right)$ shifted to more positive potentials compared with WAG/Rij ( $V_{\mathrm{h}}=-92.3 \pm 1.4 \mathrm{mV} ; n=14$ ) (Fig. $2 \mathrm{~B}$ ). Because long hyperpolarization was not readily tolerated by TC neurons, shortened activation protocols ranging from $5.5 \mathrm{~s}$ at
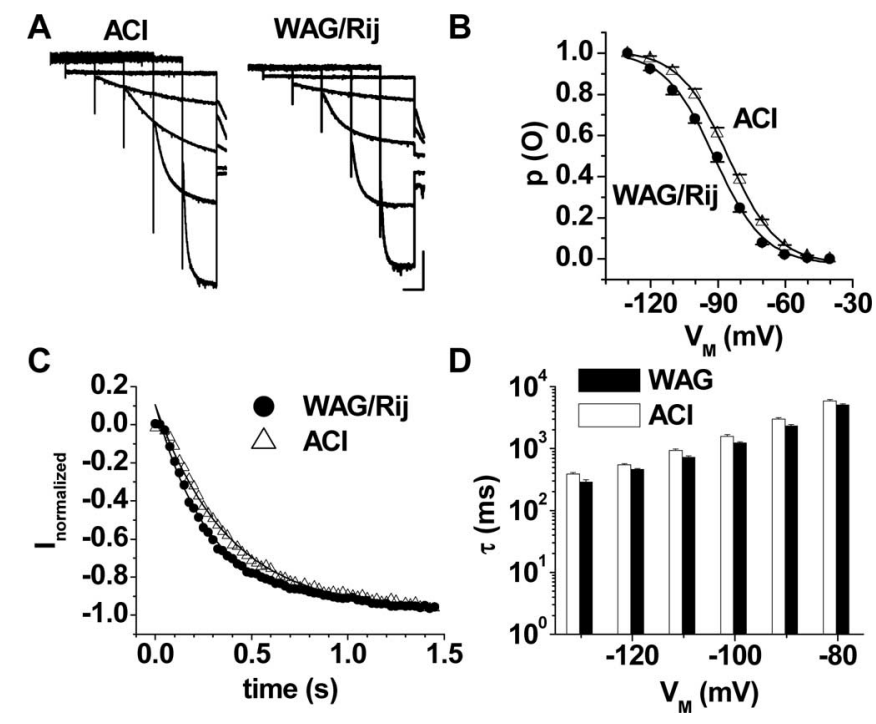

Figure 2. Basic electrophysiological properties of $I_{h}$ in TC neurons in the dLGN of epileptic and nonepileptic rat strains. $A$, Families of current traces recorded in a $\mathrm{TC}$ neuron of $\mathrm{ACl}$ (left) and WAG/Rij (right) rats. Current traces at $-50,-70,-90,-110$, and $-130 \mathrm{mV}$ are shown. Calibration bars: $2 \mathrm{~s}, 300 \mathrm{pA}$. $\boldsymbol{B}$, Mean steady-state activation curves of $I_{\mathrm{h}}$ under control conditions in TC neurons of ACl (open triangles; $n=16$ ) and WAG/Rij (filled circles; $n=14$ ) rats. Note the positive shift of the activation curve in $\mathrm{ACl}$ rats. $\boldsymbol{C}$, Monoexponential fits (continuous lines) to $I_{\mathrm{h}}$ current traces elicited by a step from -50 to $-130 \mathrm{mV}$ in $\mathrm{ACl}$ (open triangles) and WAG/Rij (filled circles) rats. $D$, Mean time constants of $I_{\mathrm{h}}$ activation plotted semilogarithmically against the step potential in TC neurons of ACI (open bars; $n=24$ ) and WAG/Rij (WAG; filled bars; $n=16$ ) rats. All differences between the two rat strains were statistically significant $\left(p<3 \times 10^{-2}\right)$.

$-50 \mathrm{mV}$ to $1.5 \mathrm{~s}$ at $-130 \mathrm{mV}$ (Ludwig et al., 2003) were used in the following and gave rise to very similar results. The construction of steady-state activation curves revealed $V_{\mathrm{h}}$ values in ACI $(-88.0 \pm 0.5 \mathrm{mV} ; n=79)$ and WAG/Rij $\left(V_{\mathrm{h}}=-93.2 \pm 0.6 \mathrm{mV}\right.$; $n=59)$, which were significantly $\left(p<1 \times 10^{-4}\right)$ more positive in nonepileptic rats. Interestingly, two other rat strains, Wistar $\left(V_{\mathrm{h}}=-88.2 \pm 0.6 \mathrm{mV} ; n=42\right)$ and Long-Evans $\left(V_{\mathrm{h}}=-84.6 \pm\right.$ $1.3 \mathrm{mV} ; n=14)$, revealed values of half-maximal $I_{\mathrm{h}}$ activation in dLGN TC neurons resembling those in the nonepileptic control strain (data not shown). Similar differences in $I_{\mathrm{h}}$ voltage dependency were observed in TC neurons recorded in the VB (ACI, $V_{\mathrm{h}}=-83.1 \pm 0.8 \mathrm{mV}, n=19 ; \mathrm{WAG} / \mathrm{Rij}, V_{\mathrm{h}}=-85.9 \pm 0.8 \mathrm{mV}$, $n=14 ; p<5 \times 10^{-3}$ ), although the steady-state activation of $I_{\mathrm{h}}$ in the VB was more depolarized compared with that in the dLGN (data not shown). The differences in $I_{\mathrm{h}}$ steady-state activation properties between TC cells from epileptic and nonepileptic animals were associated with differences in the time course of activation of $I_{\mathrm{h}}$ at a given membrane potential. Activation of $I_{\mathrm{h}}$ was well described by a monoexponential function in dLGN neurons of the two strains (Fig. 2C), and the time constant of $I_{\mathrm{h}}$ activation in WAG/Rij was significantly below that in ACI (Fig. 2D). Importantly, time constants of $I_{\mathrm{h}}$ activation were also different in the two strains at the voltage of maximal activation (Fig. $2 D$ ). In contrast, the current/voltage $(I / V)$ relationship of the fully activated $I_{\mathrm{h}}$ conductance was not different in dLGN neurons from ACI (slope, $13 \pm 1 \mathrm{mS}$; reversal potential, $-40 \pm 2 \mathrm{mV} ; n=10$ ) and WAG/Rij (slope, $16 \pm 1 \mathrm{mS}$; reversal potential, $-38 \pm 1 \mathrm{mV}$; $n=11)$. Furthermore, the $I_{\mathrm{h}}$ current density was not different in the two rat strains (WAG/Rij, $3.2 \pm 0.2 \mathrm{pA} / \mathrm{pF}, n=20$; ACI, $3.4 \pm$ $0.2 \mathrm{pA} / \mathrm{pF}, n=20)$. 
Differences in cAMP-mediated regulation of $I_{h}$ in TC neurons from epileptic and nonepileptic animals One characteristic property of HCN channels is the cAMP-evoked positive shift in the steady-state voltage dependence ( $\mathrm{S}$. Chen et al., 2001). Extracellular application of a membrane-permeable cAMP an$\operatorname{alog}$ (8-bromo-cAMP; $1 \mathrm{~mm}$ ) to dLGN TC neurons of ACI significantly $(p<6 \times$ $10^{-7}$ ) shifted the midpoint of $I_{\mathrm{h}}$ activation by $5.1 \pm 1.0 \mathrm{mV}(n=15)$ to more positive potentials (Fig. $3 A$ ), thereby resembling the effect of 8-bromo-cAMP in dLGN neurons of various species (McCormick and Pape, 1990; Budde et al., 1997). By comparison, in the same type of neuron in WAG/Rij, the shift in the $V_{\mathrm{h}}$ value induced by 8 -bromo-cAMP ( $1 \mathrm{mM})$ averaged $2.3 \pm$ $0.3 \mathrm{mV}\left(n=12 ; p<2 \times 10^{-4}\right)$ (Fig. $\left.3 B\right)$. The difference between the two strains was significant $\left(p<2 \times 10^{-2}\right)$. Similar differences $\left(p<8 \times 10^{-3}\right)$ were observed after application of the phosphodiesterase inhibitor IBMX $(100 \mu \mathrm{M})$ in that $V_{\mathrm{h}}$ was positively shifted by $5.6 \pm 0.7 \mathrm{mV}(n=14 ; p<$ $4 \times 10^{-6}$ ) (Fig. $3 C$ ) in ACI rats and by $2.6 \pm 0.5 \mathrm{mV}$ in WAG/Rij $(n=10 ; p<3 \times$ $10^{-3}$ ) (Fig. 3D).

To ensure that the same levels of cyclic nucleotides were reached in the two rat strains, dLGN TC neurons were recorded with defined concentrations of 8-bromocAMP (range, 0.01-100 $\mu \mathrm{M}$ ) included in the pipette solution. After stable recordings had been obtained at a defined 8-bromo-cAMP concentration under whole-cell conditions (see Materials and Methods), the time course and activation range of $I_{\mathrm{h}}$ were determined. The data revealed significant $(p<4.7 \times$ $10^{-2}$ ) differences between dLGN TC neurons from WAG/Rij and ACI at a range of $0.01-1 \mu \mathrm{M} 8$-bromo-cAMP but not at higher concentrations $(10-100 \mu \mathrm{M})$. Data are illustrated in Figure 4. For instance, the midpoint of $I_{\mathrm{h}}$ activation at $1 \mu \mathrm{M}$ 8-bromo-cAMP (Fig. $4 A, C)$ was significantly $\left(p<3 \times 10^{-2}\right)$ different between ACI $(-79.5 \pm 1.8 \mathrm{mV} ; n=7)$ and WAG/Rij $(-85.3 \pm 1.5 \mathrm{mV}$; $n=8$ ) (Fig. $4 B$ ), whereas activation curves at $10 \mu \mathrm{M} 8$-bromocAMP (Fig. $4 B$ ) were indistinguishable between the two strains (ACI, $-78.4 \pm 1.6 \mathrm{mV}, n=9$; WAG/Rij, $-78.9 \pm 0.6, n=7$ ) (Fig. $4 A, C$ ). For comparison, the longer activation protocol (see above) was used at an intracellular 8-bromo-cAMP concentration of $0.1 \mu \mathrm{M}$ and revealed significant $\left(p<1 \times 10^{-5}\right)$ differences between ACI $(-76.7 \pm 1.3 \mathrm{mV} ; n=14)$ and WAG/Rij $(-91.8 \pm 1.1 \mathrm{mV} ; n=14)$. Furthermore, activation time constants of $I_{\mathrm{h}}$ were highly cAMP dependent. For instance, in ACI, the time constants of $I_{\mathrm{h}}$ during a pulse step from -40 to $-80 \mathrm{mV}$ ranged from $5637 \pm 223 \mathrm{~ms}(n=5)$ at $0.01 \mu \mathrm{M}$ to $2997 \pm 481$ $(n=9)$ at $100 \mu \mathrm{M}$. By comparison, activation of the respective $I_{\mathrm{h}}$ in WAG/Rij rats was typically faster, ranging from $5022 \pm 216 \mathrm{~ms}$ $(n=11)$ at $0.01 \mu \mathrm{M}$ to $2983 \pm 185 \mathrm{~ms}(n=7)$. Differences of $I_{\mathrm{h}}$ activation kinetics between the two strains were significant $(p<$ $1.4 \times 10^{-2}$ ) under control conditions (no added cAMP; see above) and at $0.01 \mu \mathrm{M} 8$-bromo-cAMP (data not shown). The dose-dependent effect is summarized in Figure $4 D$, in which the
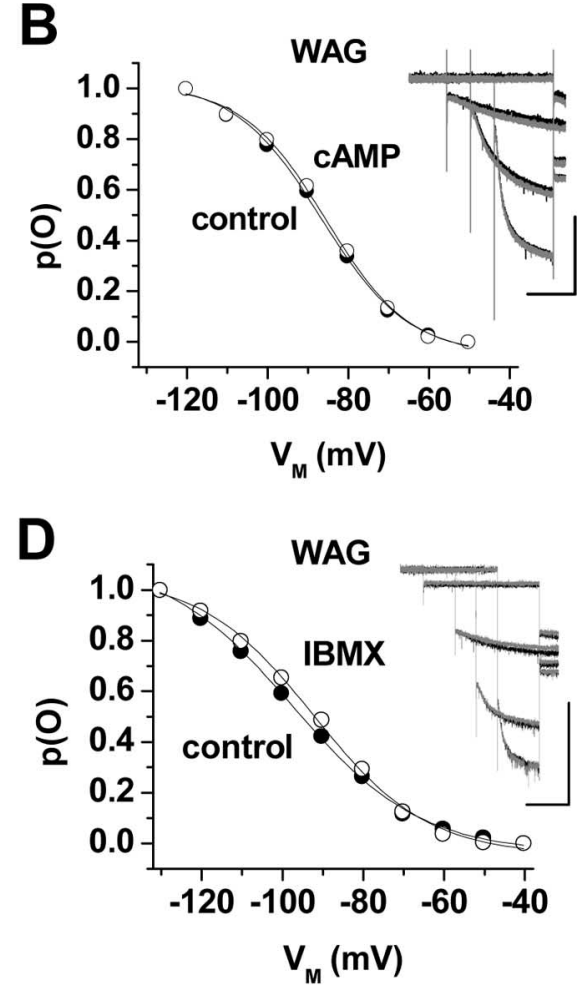

Figure 3. Modulation of $I_{\mathrm{h}}$ by exogenously applied cAMP and by endogenous cAMP production. Families of current traces recorded in TC neurons of $A C I(A, C)$ and WAG/Rij $(\boldsymbol{B}, \boldsymbol{D})$ rats under control conditions (black traces) and during substance lication (gray traces; $A, B, 1 \mathrm{~mm} 8$-bromo-CAMP; $C, D, 100 \mu \mathrm{M} \mathrm{IBMX).} \mathrm{Current} \mathrm{traces} \mathrm{at}-60,-90,-110$, and $-130 \mathrm{mV}$ are same cells. The solid lines represent best fits of a Boltzmann distribution to the data points. cAMP effect: $\mathrm{ACl}$ control (open triangles in $\boldsymbol{B}$ ), $V_{\mathrm{h}}=-87 \mathrm{mV}, k=-11 \mathrm{mV}$; WAG/Rij cAMP (open circles in $\boldsymbol{B}$ ), $V_{\mathrm{h}}=-84 \mathrm{mV}, k=-10 \mathrm{mV}$. IBMX effect: ACl control (open triangles in C), $V_{\mathrm{h}}=-89 \mathrm{mV}, k=-12 \mathrm{mV}$; ACI IBMX (filled trianglesin C), $V_{\mathrm{h}}=-82 \mathrm{mV}, k=-11 \mathrm{mV}$; WAG/Rij control (filled circles in D), $V_{\mathrm{h}}=-97 \mathrm{mV}, k=-16 \mathrm{mV}$; WAG/Rij IBMX (open circles in D), $V_{\mathrm{h}}=-94 \mathrm{mV}, k=-14$. WAG, WAG/Rij.

mean half-maximal activation of $I_{\mathrm{h}}$ is plotted against the 8-bromo-cAMP concentration. For comparison, values of $I_{\mathrm{h}}$ activation under control conditions (with no added cAMP; see above) and under conditions of deprived intracellular cAMP (through blockade of adenylyl cyclase by SQ22.536; see below) have been added to Figure $4 D$. The data show that $I_{\mathrm{h}}$ is also responsive to cAMP in TC neurons from epileptic animals, but at a higher range of concentrations compared with TC neurons from nonepileptic animals.

Next, we investigated the possibility that the ambient level of cAMP may have contributed to the observed difference in $I_{\mathrm{h}}$ properties between the epileptic and nonepileptic strains. Thalamic slices were preincubated with the adenylyl cyclase inhibitor SQ22.536 (300 $\mu \mathrm{M}, 45 \mathrm{~min})$ before electrophysiological recordings. Under these conditions, the $I_{\mathrm{h}}$ activation curves were no longer different between the two rat strains in TC neurons of the dLGN (ACI, $V_{\mathrm{h}}=-91.6 \pm 1.3 \mathrm{mV}, n=18 ; \mathrm{WAG} / \mathrm{Rij}, V_{\mathrm{h}}=-93.6 \pm 0.9 \mathrm{mV}$, $n=18$ ) (Figs. $5 A, 4 D)$ and the $\mathrm{VB}\left(\mathrm{ACI}, V_{\mathrm{h}}=-85.9 \pm 1.1 \mathrm{mV}, n=\right.$ 11; WAG/Rij, $V_{\mathrm{h}}=-84.3 \pm 0.7 \mathrm{mV}, n=10$; data not shown). Application of IBMX to SQ22.536-treated slices had no influence on $I_{\mathrm{h}}$ in dLGN TC neurons from ACI $\left(V_{\mathrm{h}}=-93.5 \pm 1.7 \mathrm{mV} ; n=3\right)$ and WAG/Rij $\left(V_{\mathrm{h}}=-95.3 \pm 1.6 \mathrm{mV} ; n=4\right)($ Fig. $5 \mathrm{~A})$, indicating an effective block of basal adenylyl cyclase activity by SQ22.536. Nevertheless, extracellular application of 8-bromo-cAMP (1 mM) significantly shifted the $I_{\mathrm{h}}$ activation curve to more positive potentials in TC neurons both from ACI $\left(9.7 \pm 1.5 \mathrm{mV} ; n=8 ; p<2 \times 10^{-4}\right)$ (Fig. $5 B)$ and WAG/Rij ( $4.4 \pm 1.3 \mathrm{mV} ; n=9 ; p=1 \times 10^{-2}$ ) (Fig. 


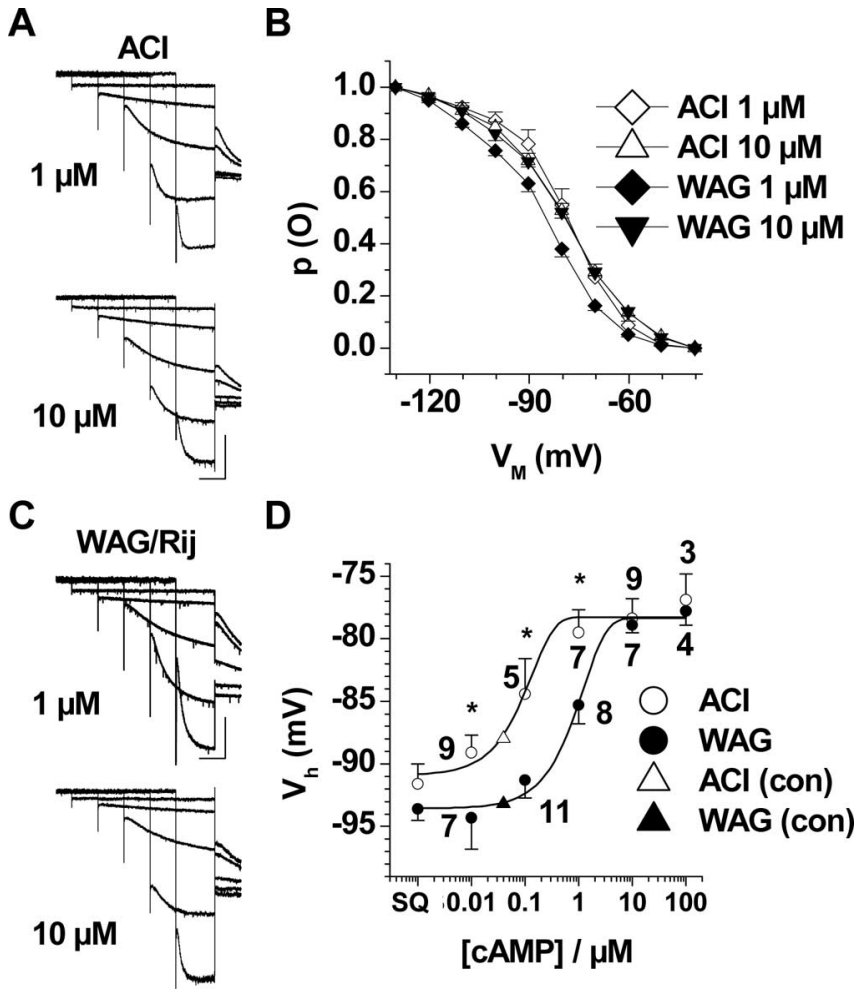

Figure 4. Modulation of $I_{\mathrm{h}}$ by defined intracellular CAMP concentrations. $A, C$, Families of current traces recorded in $\mathrm{TC}$ neurons of $\mathrm{ACl}(\boldsymbol{A})$ and WAG/Rij $(\boldsymbol{C})$ rats obtained after loading of the cells with $1 \mu \mathrm{M}$ (top) and $10 \mu \mathrm{M}$ (bottom) 8-bromo-cAMP. Current traces at $-50,-70$, $-90,-110$, and $-130 \mathrm{mV}$ are shown. Calibration bars: 1 s, 300 pA. $\boldsymbol{B}$, Mean steady-state activation curves of $I_{\mathrm{h}}$ at different intracellular CAMP concentrations in TC neurons from ACl (1 $\mu \mathrm{M}$ CAMP, open diamonds, $n=5 ; 10 \mu \mathrm{M}$ cAMP, open triangles, $n=9)$ and WAG/Rij $(1 \mu \mathrm{M}$, filled diamonds, $n=11 ; 10 \mu \mathrm{m}$, filled triangles, $n=7$ ). $\boldsymbol{D}$, Dose-response curve of cAMP applied via the intracellular solution. The mean half-maximal activation of $/ \mathrm{h}$ is plotted against the CAMP concentration for TC neurons from ACI (open circles) and WAG/Rij (filled circles). The numbers near the symbols indicate number of recorded cells; differences between epileptic and nonepileptic strains are significant $\left({ }^{*} p<4.7 \times 10^{-2}\right)$ at $0.01,0.1$, and $1 \mu \mathrm{M}$ cAMP. The triangles indicate endogenous cAMP levels in TC neurons of ACI (open triangle) and WAG/Rij (filled triangle), as extrapolated from the values of half-maximal $I_{\mathrm{h}}$ activation with no addition of cAMP to the recording pipette (see Fig. 2 B). WAG, WAG/Rij; con, control. Error bars represent SEM.

$5 C)$, but the effect was significantly smaller in WAG/Rij than in ACI $\left(p<2 \times 10^{-2}\right)$. Together, these data indicated a reduction in cAMP sensitivity of $I_{\mathrm{h}}$ in TC neurons from epileptic and nonepileptic rats.

cAMP-induced changes in activity mode of TC neurons

TC neurons can generate two different patterns of electrical activity, dependent on the prevailing membrane potential (Steriade et al., 1997). At membrane potentials negative from rest, depolarizing stimuli elicit a burst of fast spikes triggered by a low threshold-activated T-type $\mathrm{Ca}^{2+}$ current; at membrane potentials positive to rest, $I_{\mathrm{T}}$ is inactivated and depolarizing stimuli evoke tonic series of $\mathrm{Na}^{+} / \mathrm{K}^{+}$-mediated action potentials. We tested the possible functional relevance of altered $I_{\mathrm{h}}$ properties in dLGN TC neurons from WAG/Rij and ACI recorded under current-clamp conditions. Barium $\left(\mathrm{Ba}^{2+} ; 150 \mu \mathrm{M}\right)$ was added to the bathing medium to block inwardly rectifying $\mathrm{K}^{+}$currents, a cAMP-depending leakage current, and TWIK (tandem of $\mathrm{P}$-domains in a weakly inward rectifying $\mathrm{K}^{+}$channel)-related acid-sensitive $\mathrm{K}^{+}$channels (Budde et al., 1997; Meuth et al., 2003), which interfere with activation of $I_{\mathrm{h}}$ at membrane potentials at or negative from rest. Under these experimental condi-
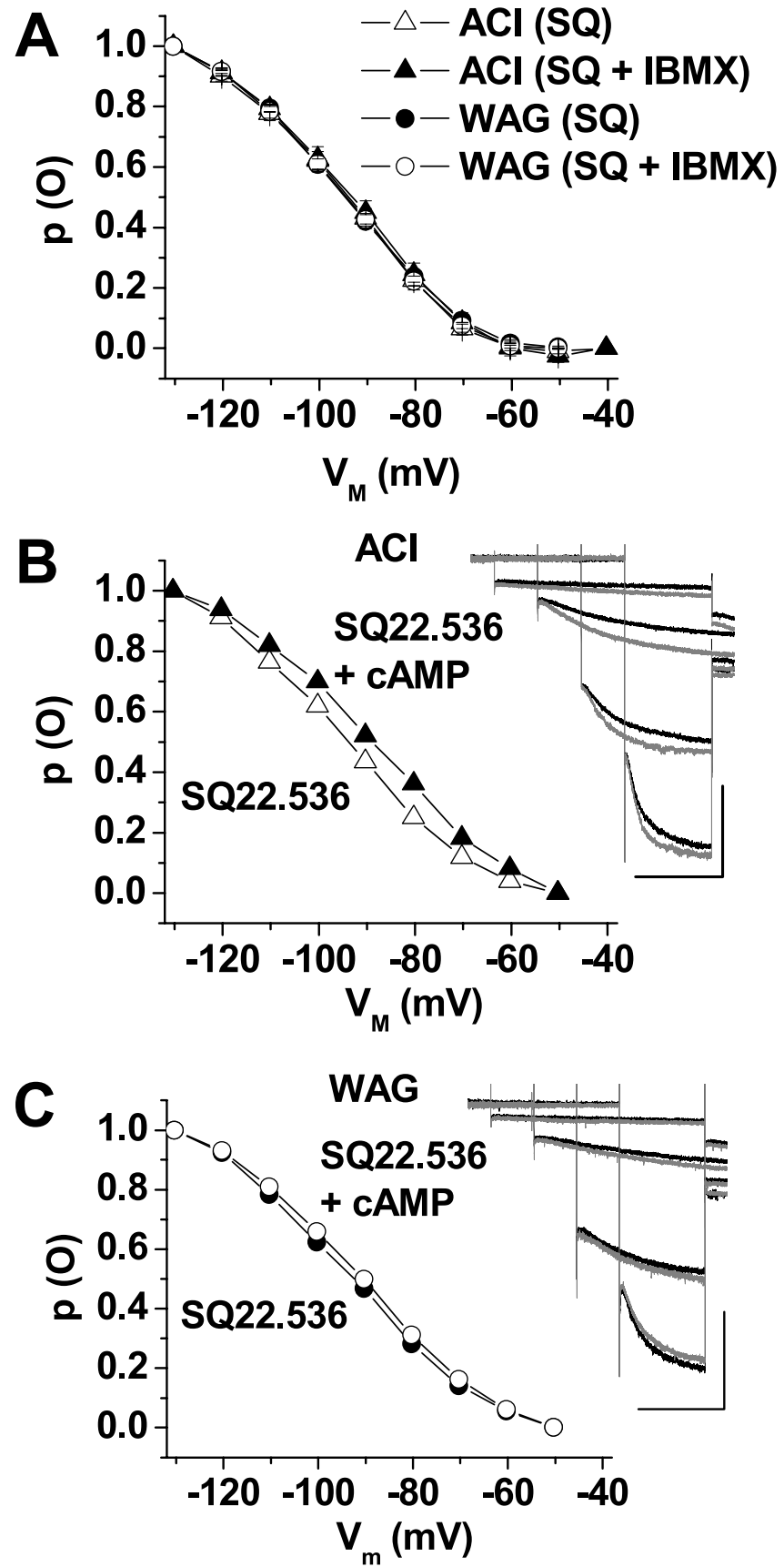

Figure 5. Modulation of $I_{\mathrm{h}}$ after adenylyl cyclase inhibition. $A$, Mean steady-state activation curves of $I_{h}$ in dLGN after preincubation with SQ22.536 (300 $\mu \mathrm{m}$; ACl, open triangles; WAG/Rij, filled circles) and consecutive application of IBMX (100 $\mu \mathrm{m} ; \mathrm{ACl}$, open circles; WAG/Rij, filled circles). $\boldsymbol{B}, \boldsymbol{C}$, Families of current traces recorded in $\mathrm{dLGN}$ neurons of $\mathrm{ACl}(\boldsymbol{B})$ and WAG/Rij $(\boldsymbol{C})$ rats after preincubation with SQ22.536 (300 $\mu \mathrm{m}$; black traces) and subsequent extracellular application of 8-bromo-CAMP (1 mm; gray traces). Current traces at $-60,-90,-110$, and -130 $\mathrm{mV}$ are shown. Calibration bars: $2 \mathrm{~s}, 300 \mathrm{pA}$. The main panels show the corresponding steady-state activation curves derived from the same cells [ACl control (open triangles in $B$ ), $V_{\mathrm{h}}=-95 \mathrm{mV}, k=-16 \mathrm{mV}$; ACl CAMP (filled triangles in $\boldsymbol{B}$ ), $V_{\mathrm{h}}=-88 \mathrm{mV}, k=$ $-17 \mathrm{mV}$; WAG/Rij control (filled circles in $C$ ), $V_{\mathrm{h}}=-94 \mathrm{mV}, k=-17 \mathrm{mV}$; WAG/Rij cAMP (open circles in $C$ ), $V_{\mathrm{h}}=-91 \mathrm{mV}, k=-17 \mathrm{mV}$ ]. WAG, WAG/Rij; SQ, SQ22.536.

tions, resting membrane potential (WAG/Rij, $-64.1 \pm 1.1 \mathrm{mV}$, $n=8 ; \mathrm{ACI},-61.0 \pm 2.2 \mathrm{mV}, n=7$ ) and input resistance (WAG/ Rij, $2.8 \pm 0.9 \mathrm{G} \Omega, n=8$; ACI, $2.0 \pm 0.5 \mathrm{G} \Omega, n=7$ ) were not different in TC neurons in the two rat strains. To induce robust burst activity, TC neurons were held at a membrane potential of $-70.9 \pm 0.1 \mathrm{mV}(n=15)$. Under these conditions, depolarizing 
current pulses (50-75 pA, $300 \mathrm{~ms}$ duration) elicited typical low-threshold $\mathrm{Ca}^{2+}$. spikes (LTSs) with two to six fast $\mathrm{Na}^{+} / \mathrm{K}^{+}$ action potentials riding on top (Fig. 6). Application of $100 \mu \mathrm{M} \operatorname{IBMX}(9-10 \mathrm{~min})$ to TC neurons of ACI resulted in a slow depolarization of the membrane potential to $-64.7 \pm 0.4 \mathrm{mV}(n=3)$ (Fig. $6 \mathrm{~A}$, open triangles). This effect was accompanied by a change in firing pattern from burst to tonic and was reversible (Fig. $6 \mathrm{~B}$ ). In contrast, application of IBMX to TC neurons in WAG/Rij evoked a depolarization from the holding potential to only $-67.4 \pm 0.4$ $\mathrm{mV}(n=4)$ (Fig. $6 A$ filled circles), which was not sufficient to change the firing pattern from burst to tonic (Fig. 6C). The average depolarizing effect of IBMX was significantly $\left(p<1 \times 10^{-3}\right)$ smaller in WAG/Rij compared with ACI. Similar results were obtained after application of 8-bromo-cAMP (1 $\mathrm{mM}, 14-15 \mathrm{~min}$ ) in that the resulting depolarization shifted the firing pattern from burst to tonic in TC neurons from ACI but not WAG-Rij (Fig. $6 E, F)$. On average, the 8-bromo-cAMPevoked depolarization was significantly $\left(p<1 \times 10^{-3}\right)$ smaller in WAG/Rij $(-67.3 \pm 0.2 \mathrm{mV} ; n=3)$ (Fig. $6 \mathrm{D}$ filled circles) compared with ACI $(-66.3 \pm 0.2$ $\mathrm{mV} ; n=4)$ (Fig. $6 D$, open triangles).

\section{Reverse transcription-PCR analysis of HCN isoform expression}

To test whether the differences in $I_{\mathrm{h}}$ properties observed in TC neurons from ACI and WAG/Rij are based on differences in HCN gene expression, we designed a multiplex reverse transcription-PCR (RT-PCR) protocol to simultaneously detect $\mathrm{HCN} 1-4$ channels in rat brain slices. In the dLGN of both strains, mRNA of the four HCN isoforms was detected. Whereas HCN2, HCN3, and HCN4 revealed strong PCR signals, HCN1 mRNA was detectable in WAG/ Rij rats but barely expressed in ACI rats (Fig. 7A). Next, we used semiquantitative PCR analysis of all $\mathrm{HCN}$ isoforms, with G3PDH and $\beta$-actin as internal standards, and assessed the expression of HCN isoforms from dLGN preparations in WAG/Rij and ACI (Fig. 7B). The mRNA expression level of the HCN1 isoform was $3.67 \pm 0.04$ times higher in WAG/Rij compared with ACI $(p<$ $1 \times 10^{-2}$; seven independent dLGN preparations were used for each rat strain and compared pair-wise during semiquantitative PCR analysis), whereas no significant differences were found for the mRNA expression of the other $\mathrm{HCN}$ isoforms in the two rat strains (ratio of expression WAG/Rij divided by ACI; HCN2, $0.89 \pm 0.04 ; \mathrm{HCN} 3,1.03 \pm 0.07 ; \mathrm{HCN} 4,0.92 \pm 0.06)$. These findings were corroborated by two independent lines of evidence. A real-time RT-PCR approach (after normalization to a passive reference dye and mRNA of the housekeeping gene $\beta 2$ microglobulin) indicated that HCN1 expression in WAG/Rij rats is $3.85 \pm 0.53$ times higher compared with ACI rats $(p<1 \times$ $10^{-2} ; 10$ independent dLGN preparations were used for each rat strain) (Fig. 7C) . Furthermore, HCN1 protein levels were assessed through semiquantitative Western blot analysis of dLGN tissue using a HCN1-specific antibody (Fig. 7D). Data from multiple independent preparations revealed an increase in HCN1 protein level by a factor of $2.13 \pm 0.18$ in WAG/Rij compared with ACI $\left(p<1 \times 10^{-2}\right.$; eight protein preparations from dLGN were used for each rat strain).

In a next experimental step, the expression of $\mathrm{HCN}$ isoforms in TC neurons was demonstrated through in situ hybridization and immunohistochemistry/in situ hybridization double labeling. The use of isoform-specific digoxigenin-labeled antisense RNA probes revealed a dense and strong expression of $\mathrm{HCN} 2$ and HCN4 mRNA in the dLGN of both rat strains (Fig. $8 B, C$ ). Furthermore, HCN1 mRNA was expressed weakly in ACI (Fig. $8 A$, right) but was readily detectable in WAG/Rij (Fig. $8 A$, left). To confirm that $\mathrm{HCN} 1$ isoforms are expressed in TC neurons, in situ hybridization for HCN1 was combined with immunohistochemical labeling of parvalbumin, a TC neuron-specific cell marker in the dLGN of several species (Jones and Hendry, 1989; Sieg et al., 1998; Meuth et al., 2005). The large majority of parvalbuminpositive neurons in the dLGN of WAG/Rij were positive for HCN1, whereas parvalbumin-immunonegative HCN1-positive neurons were rarely detected (Fig. 8D). The size and shape of double-labeled cells were reminiscent of multipolar neurons, which are thought to represent TC neurons in the dLGN (Gabbott et al., 1986). In a representative sample of slices $(n=16)$, $87 \pm 2 \%$ of the parvalbumin-positive cells $(n=1687)$ were also positive for HCN1. 

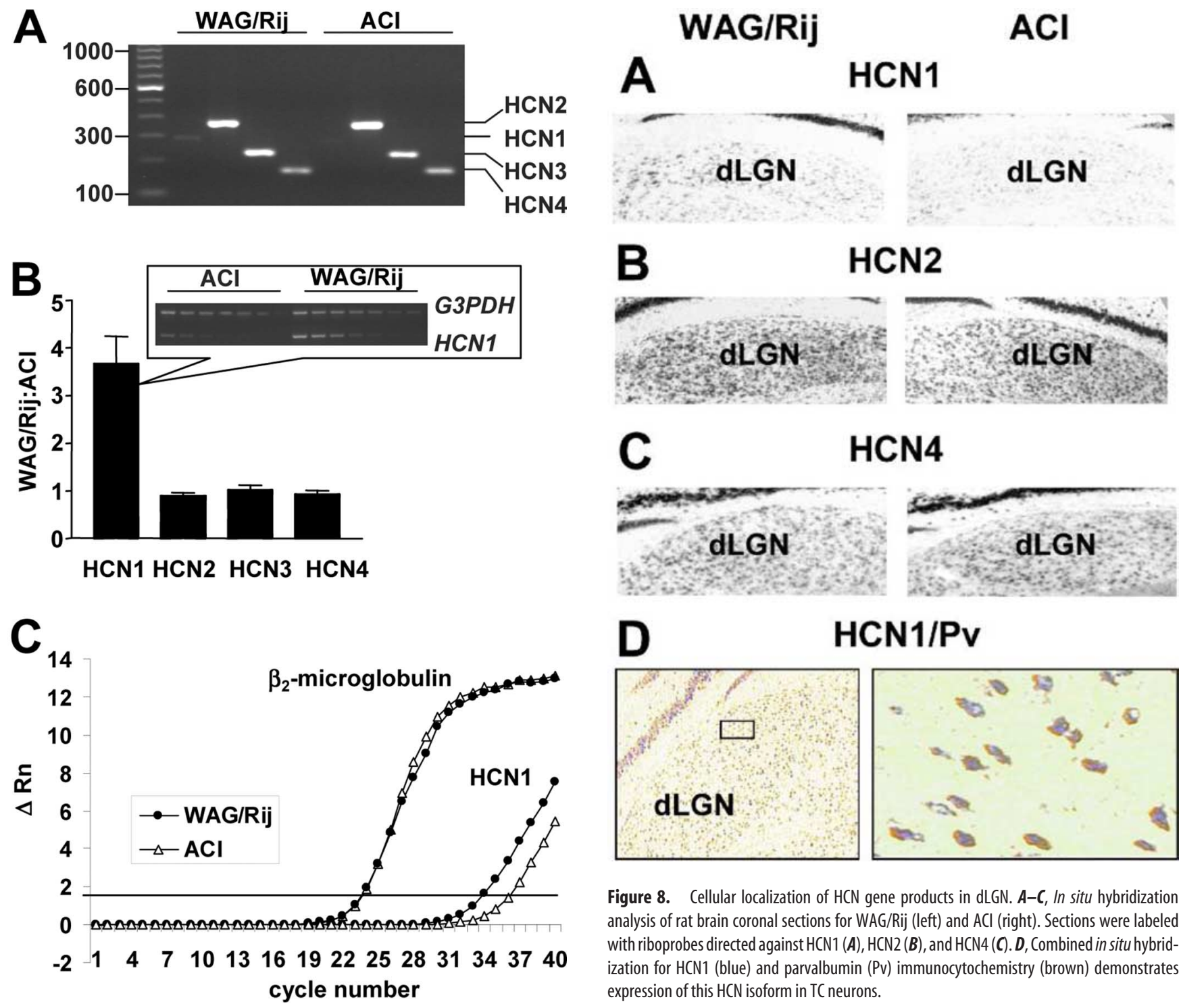

D HCN1/Pv

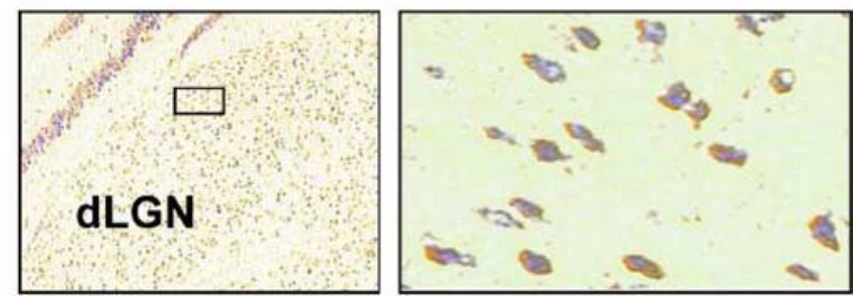

Figure 8. Cellular localization of HCN gene products in $\mathrm{dLGN}$. $\boldsymbol{A}-\boldsymbol{C}$, In situ hybridization analysis of rat brain coronal sections for WAG/Rij (left) and ACI (right). Sections were labeled with riboprobes directed against HCN1 $(\boldsymbol{A}), \mathrm{HCN} 2(\boldsymbol{B})$, and HCN4 (C). D. Combined in situ hybridization for HCN1 (blue) and parvalbumin (Pv) immunocytochemistry (brown) demonstrates expression of this $\mathrm{HCN}$ isoform in TC neurons.

D

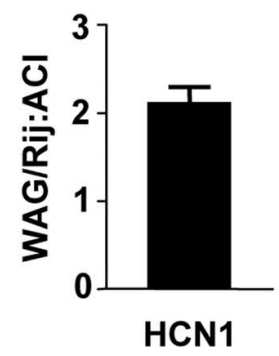

Figure 7. Expression pattern and level of HCN mRNA in dLGN. $\boldsymbol{A}, \mathrm{RT}-\mathrm{PCR}$ expression profiles of HCN1-4 after 30 amplification cycles, initial cDNA concentration of $10 \mathrm{pg}$. $\boldsymbol{B}$, Differences in mRNA expression of HCN1 -4 determined by semiquantitative RT-PCR; inset shows an example of a corresponding PCR profile. C, Real-time PCR amplification plots for HCN1 and $\beta 2$ microglobulin. $\Delta R n$, Normalized and baseline-corrected fluorescence signal. $\boldsymbol{D}$, Protein expression of HCN1. WAG, WAG/Rij. Error bars represent SEM.

\section{Discussion}

The present study indicates a recruitment of $I_{\mathrm{h}}$ in TC neurons during spike-and-wave discharges accompanying spontaneous seizures in a rat model of absence epilepsy, an alteration of the basic electrophysiological properties of $I_{\mathrm{h}}$, and increased expression of HCN1 in TC neurons of epileptic WAG/Rij rats compared with nonepileptic control strains (ACI). Functionally, the reduced responsiveness to cAMP prevents the shift from burst to tonic firing modes after increases in the intracellular cAMP level occurring at ages before spontaneous seizure activity is evident (Renier and Coenen, 2000). Therefore, the alteration in $I_{\mathrm{h}}$ properties may relate to the generation of seizures rather than being induced by seizures.

Expression of $\mathrm{HCN}$ isoforms related to $I_{\mathrm{h}}$ properties in TC neurons

The four HCN channels display different voltage-dependent properties and modulation by CAMP, there is evidence for the formation of heteromeric channels, and the properties of $I_{\mathrm{h}}$ recorded in various cell types correlate with the mRNA expression profile of HCN genes (Santoro et al., 2000; Much et al., 2003; Santoro and Baram, 2003). Of particular interest here is that HCN1 channels are characterized by fast kinetics of activation, a rather positive voltage range of activation, and low cAMP sensitivity (Santoro and Baram, 2003). Indeed, $I_{\mathrm{h}}$ in TC neurons, which mostly express HCN2 and HCN4, possesses slower kinetics and higher cAMP sensitivity than, for instance, $I_{\mathrm{h}}$ in CA1 
pyramidal neurons, which mostly express HCN1 and HCN2 (Franz et al., 2000; Santoro et al., 2000). The following line of evidence indicates that the reduced cAMP sensitivity and faster kinetics of $I_{\mathrm{h}}$ activation observed in individual TC neurons from WAG/Rij rats compared with ACI seem is correlated with the increase in HCN1: (1) HCN1 expression mostly localizes to parvalbumin-immunopositive cells in thalamic relay nuclei, representing the population of TC neurons (Jones and Hendry, 1989; Sieg et al., 1998; Meuth et al., 2005). (2) The selective alteration in $\mathrm{HCN} 1$ expression, with unaltered $\mathrm{HCN} 2-4$ expression, in thalamic relay nuclei from epileptic versus nonepileptic animals, and the unchanged passive membrane properties and $I_{\mathrm{h}}$ current densities in the respective TC neurons, vote against more general influences, such as neuronal morphologies. (3) The difference in the $I_{\mathrm{h}}$ activation curve with no difference in the fully activated $I / V$ observed in TC neurons between the two rat strains reflect the profile of cAMP action on $I_{\mathrm{h}}$ in these neurons (McCormick and Pape, 1990; Pape, 1996). (4) Negative shifts in the $I_{\mathrm{h}}$ activation curve in TC neurons are indicative of responses that are negatively coupled to the intracellular cAMP system (Pape, 1992). (5) The similar basal $I_{\mathrm{h}}$ activation curve and the difference in cAMP-evoked shifts of $I_{\mathrm{h}}$ activation during pharmacological blockade of endogenous adenylyl cyclase activity are explained best by a change in sensitivity toward cAMP. This finding also votes against the possible contribution of technical constraints, relating, for instance, to the somato-dendritic distribution of the $I_{\mathrm{h}}$ channels. (6) Differences in cAMP sensitivity of $I_{\mathrm{h}}$ occur at $0.01-1 \mu \mathrm{M}$ but not at lower or higher concentrations of cAMP, thereby indicating a shift of the CAMP dose-response curve toward higher cyclic nucleotide concentrations, which is within the range of physiological cytosolic cyclic nucleotide levels (0.02-1.5 $\mu \mathrm{M}$ ) and stimulus-induced concentrations changes (maximally 5 $\mu \mathrm{M}$ ) (Adams et al., 1991; Trivedi and Kramer, 1998; Zaccolo et al., 2000; Heine et al., 2002). It should be taken into consideration that 8-bromo-cAMP may not well penetrate the slice and, thus, that the recordings obtained in $1 \mathrm{~mm}$ extracellular 8-bromocAMP are at steady state rather than at equilibrium. In line with the results obtained with defined concentrations of intracellular 8-bromo-cAMP, it may be concluded that 8-bromo-cAMP achieves no higher intracellular concentration than $\sim 1 \mu \mathrm{M}$, implying that the gating of $I_{\mathrm{h}}$ is only partially facilitated, although to a different extend, in the two rat strains.

The finding that an increase in HCN1, despite its rather low overall expression level, is associated with significant changes of $I_{\mathrm{h}}$ properties in TC neurons should be interpreted in light of the following evidence: (1) $I_{\mathrm{h}}$ in TC neurons appears to be dominated by $\mathrm{HCN} 2$ ( $80 \%$ reduction in amplitude in HCN2-deficient mice) and slowed in activation kinetics by the contribution of HCN4 (Franz et al., 2000; Santoro et al., 2000; Ludwig et al., 2003). (2) Heterologous expression studies indicate that HCN1 subunits impose a positive shift to the $I_{\mathrm{h}}$ activation curve associated with faster kinetics and low cAMP sensitivity (Robinson and Siegelbaum, 2003). (3) The activation range of HCN2, but not HCN1, depends on basal adenylyl cyclase activity (Ulens and Tytgat, 2001b). (4) Functional HCN1/HCN2 heteromers reveal steady-state activation properties and cAMP dependency that are rather $\mathrm{HCN} 2$ dominated, whereas activation time constants are rather HCN1 dominated (Ulens and Tytgat, 2001a). (5) In hippocampal areas, the ratio of $\mathrm{HCN} 1$ and $\mathrm{HCN} 2$ expression is changed in febrile seizures and leads to augmented formation of HCN1/HCN2 heteromerization (K. Chen et al., 2001; Brewster et al., 2002, 2005; Bender et al., 2003). The properties of $I_{\mathrm{h}}$ after febrile seizures resembles neither those of heterologously ex- pressed homomeric HCN1 or HCN2 channels nor their arithmetic intermediates (S. Chen et al., 2001; Ulens and Tytgat, 2001a). (6) Therefore, it seems feasible to conclude that the basic range of steady-state voltage dependency and cAMP sensitivity of $I_{\mathrm{h}}$ in TC neurons is primarily determined through HCN2, whereas the slow activation kinetics reflects the contribution of $\mathrm{HCN} 4$. Addition of HCN1 can modulate $I_{\mathrm{h}}$ kinetics and basic cAMP responsiveness. As a result of the low overall expression level, an increase in HCN1 expression does not shift the $I_{\mathrm{h}}$ voltage dependence and kinetics from a HCN2/4- into a HCN1dominated form but merely modulates the cAMP sensitivity within a physiological range of concentrations. The molecular elements connecting the increase in $\mathrm{HCN} 1$ expression to the decrease in CAMP sensitivity and altered voltage dependency are unknown at present but may relate to functional interactions between the various subunits in heteromultimeric $I_{\mathrm{h}}$ channels (Yu et al., 2001; Decher et al., 2003; Much et al., 2003), alterations in allosteric $I_{\mathrm{h}}$ regulation (Wang et al., 2002), and/or differences in cAMP/cGMP pathways known to affect $I_{\mathrm{h}}$ in TC neurons (Lüthi and McCormick, 1998a, 1999; Frere and Lüthi, 2004).

\section{Regulation of $\mathrm{HCN}$ expression related to epileptic seizures}

HCN gene expression changes as the consequence of developmental processes (Bender et al., 2001), neuronal activity (K. Chen et al., 2001), and epileptic seizures (Brewster et al., 2002; Bender et al., 2003). An increase in maximal $I_{\mathrm{h}}$ amplitude lowered the threshold of febrile seizures in rats (K. Chen et al., 2001) as well as neocortical SWD in the stargazer mouse (Di Pasquale et al., 1997). The balance of HCN1 and HCN2 expression may be critical for seizure activity because genetic knock-out of the HCN2 isoform (Ludwig et al., 2003) and a reduction of HCN1 protein expression in the neocortex (Strauss et al., 2004) is associated with absence-like activity in HCN2 knock-out mice and WAG/ Rij rats, respectively. The present study extends those observations in that it reveals a selective increase in $\mathrm{HCN} 1$ expression in TC neurons of a rat genetic model of absence epilepsy, which is associated with an impaired cAMP-dependent $I_{\mathrm{h}}$ regulation and hence an impaired regulation of burst activity in the thalamus (see below). Together, the available evidence suggests a regionaland isoform-specific regulation of HCN gene expression related to seizure generation and/or epileptogenesis.

\section{Contribution of $I_{\mathrm{h}}$ in TC neurons to spike-and-wave discharges}

In TC neurons of two genetic rat models (WAG/Rij, GAERS), burst discharges are locked to the spike component on the EEG (Inoue et al., 1993; Seidenbecher et al., 1998). Spike-locked discharges in TC neurons, in turn, reflect bursts of action potentials triggered by a low-threshold T-type $\mathrm{Ca}^{2+}$ current, which are activated as rebound during barrages of $\mathrm{GABA}_{\mathrm{A}}$-mediated IPSPs (Pinault et al., 1998; Staak and Pape, 2001; Destexhe and Sejnowski, 2003). An involvement of $I_{\mathrm{h}}$ in burst discharges of TC neurons during absence seizures is indicated by the present finding that local application of $I_{\mathrm{h}}$ blockers interfered with the strict spike-locked burst pattern. In thalamic slices, the periodic activation and deactivation of $I_{\mathrm{h}}$ is thought to shape the waxing and waning sequence of spindle-like burst firing in TC neurons, which is replaced by more irregular patterns during action of $I_{\mathrm{h}}$ blockers (Lüthi et al., 1998; Lüthi and McCormick, 1998a, 1999). The positive shift of the $I_{\mathrm{h}}$ activation curve resulting from an increase in intracellular cAMP concentration accompanying $\mathrm{Ca}^{2+}$-mediated burst firing is an important mechanism for termination of the bursts (Lüthi and McCormick, 1998b, 1999). In contrast, a negative shift in the $I_{\mathrm{h}}$ activation curve promotes burst 
firing in TC neurons in vitro (Pape, 1992). The increase in HCN1 expression, the decrease in cAMP sensitivity, and the negative shift of the activation curve of $I_{\mathrm{h}}$ in TC neurons from WAG/Rij may thus interfere with the termination of spike-locked burst firing, resulting in facilitation and/or prolongation of synchronized activity in thalamic circuits related to seizure generation. More specifically, the following scenario emerges from the data: (1) Spindle rhythm during sleep and SWD during absence seizures are sustained by very similar mechanisms and synaptic networks of the thalamocortical system (Destexhe and Sejnowski, 2003; Steriade, 2003). (2) $I_{\mathrm{h}}$ makes a significant contribution to both burst patterns. (3) Regulation of $I_{\mathrm{h}}$ through cAMP effectively terminates spindle-like burst firing in vitro (Lüthi and McCormick, 1999). (4) The decrease in cAMP sensitivity of $I_{\mathrm{h}}$ in TC neurons from epileptic animals will prevent an effective regulation of $I_{\mathrm{h}}$ and hence an effective termination of burst firing (present study). As a conclusion, the alteration in $I_{\mathrm{h}}$ properties will facilitate and/or prolong the generation of SWD-locked burst firing related to absence seizures, indicating a cellular dysfunction that makes a direct contribution to this pathological condition. In support of this is the observation that the knock-out of the $\mathrm{HCN} 2$ gene and resulting reduction in magnitude and cAMP responsiveness of $I_{\mathrm{h}}$ in TC neurons promote the spontaneous occurrence of absence seizure-like activity (Ludwig et al., 2003). Thus, the balance of HCN1 and HCN2 gene expression in TC neurons seems to be critical for the regulation of burst firing in thalamic networks toward either spindle-like or spike-wave-like patterns.

\section{References}

Adams SR, Harootunian AT, Buechler YJ, Taylor SS, Tsien RY (1991) Fluorescence ratio imaging of cyclic AMP in single cells. Nature 349:694-697.

Bender RA, Brewster A, Santoro B, Ludwig A, Hofmann F, Biel M, Baram TZ (2001) Differential and age-dependent expression of hyperpolarizationactivated, cyclic nucleotide-gated cation channel isoforms 1-4 suggests evolving roles in the developing rat hippocampus. Neuroscience 106:689-698.

Bender RA, Soleymani SV, Brewster AL, Nguyen ST, Beck H, Mathern GW, Baram TZ (2003) Enhanced expression of a specific hyperpolarizationactivated cyclic nucleotide-gated cation channel $(\mathrm{HCN})$ in surviving dentate gyrus granule cells of human and experimental epileptic hippocampus. J Neurosci 23:6826-6836.

Brewster A, Bender RA, Chen Y, Dube C, Eghbal-Ahmadi M, Baram TZ (2002) Developmental febrile seizures modulate hippocampal gene expression of hyperpolarization-activated channels in an isoform- and cellspecific manner. J Neurosci 22:4591-4599.

Brewster AL, Bernard JA, Gall CM, Baram TZ (2005) Formation of heteromeric hyperpolarization-activated cyclic nucleotide-gated (HCN) channels in the hippocampus is regulated by developmental seizures. Neurobiol Dis 19:200-207.

Budde T, Biella G, Munsch T, Pape H-C (1997) Lack of regulation by intracellular $\mathrm{Ca}^{2+}$ of the hyperpolarization-activated cation current in rat thalamic neurons. J Physiol (Lond) 503:79-85.

Chen K, Aradi I, Thon N, Eghbal-Ahmadi M, Baram TZ, Soltesz I (2001) Persistently modified h-channels after complex febrile seizures convert the seizure-induced enhancement of inhibition to hyperexcitability. Nat Med 7:331-337.

Chen K, Aradi I, Santhakumar V, Soltesz I (2002) H-channels in epilepsy: new targets for seizure control? Trends Pharmacol Sci 23:552-557.

Chen S, Wang J, Siegelbaum SA (2001) Properties of hyperpolarizationactivated pacemaker current defined by coassembly of HCN1 and HCN2 subunits and basal modulation by cyclic nucleotide. J Gen Physiol 117:491-504.

Chevaleyre V, Castillo PE (2002) Assessing the role of Ih channels in synaptic transmission and mossy fiber LTP. Proc Natl Acad Sci USA 99:9538-9543.
Coenen AM, Van Luijtelaar EL (2003) Genetic animal models for absence epilepsy: a review of the WAG/Rij strain of rats. Behav Genet 33:635-655.

Crunelli V, Leresche N (2002) Childhood absence epilepsy: genes, channels, neurons and networks. Nat Rev Neurosci 3:371-382.

Decher N, Bundis F, Vajna R, Steinmeyer K (2003) KCNE2 modulates current amplitudes and activation kinetics of HCN4: influence of KCNE family members on HCN4 currents. Pflügers Arch 446:633-640.

Destexhe A, Sejnowski TJ (2003) Interactions between membrane conductances underlying thalamocortical slow-wave oscillations. Physiol Rev 83:1401-1453.

Di Pasquale E, Keegan KD, Noebels JL (1997) Increased excitability and inward rectification in layer $\mathrm{V}$ cortical pyramidal neurons in the epileptic mutant mouse Stargazer. J Neurophysiol 77:621-631.

Dodt HU, Zieglgänsberger W (1990) Visualizing unstained neurons in living brain slices by infrared DIC-videomicroscopy. Brain Res 537:333-336.

Felix R, Sandoval A, Sanchez D, Gomora JC, De la Vega-Beltran JL, Trevino CL, Darszon A (2003) ZD7288 inhibits low-threshold Ca ${ }^{2+}$ channel activity and regulates sperm function. Biochem Biophys Res Commun 311:187-192.

Franz O, Liss B, Neu A, Roeper J (2000) Single-cell mRNA expression of HCN1 correlates with a fast gating phenotype of hyperpolarizationactivated cyclic nucleotide-gated ion channels (Ih) in central neurons. Eur J Neurosci 12:2685-2693.

Frere SG, Lüthi A (2004) Pacemaker channels in mouse thalamocortical neurones are regulated by distinct pathways of cAMP synthesis. J Physiol (Lond) 554:111-125.

Gabbott PL, Somogyi J, Stewart MG, Hamori J (1986) A quantitative investigation of the neuronal composition of the rat dorsal lateral geniculate nucleus using GABA-immunocytochemistry. Neuroscience 19:101-111.

Heine M, Ponimaskin E, Bickmeyer U, Richter DW (2002) 5-HT-receptorinduced changes of the intracellular cAMP level monitored by a hyperpolarization-activated cation channel. Pflügers Arch 443:418-426.

Inoue M, Duysens J, Vossen JM, Coenen AM (1993) Thalamic multipleunit activity underlying spike-wave discharges in anesthetized rats. Brain Res 612:35-40.

Inoue M, Ates N, Vossen JM, Coenen AM (1994) Effects of the neuroleptanalgesic fentanyl-fluanisone (Hypnorm) on spike-wave discharges in epileptic rats. Pharmacol Biochem Behav 48:547-551.

Jones EG, Hendry SH (1989) Differential calcium binding protein immunoreactivity distinguishes classes of relay neurons in monkey thalamic nuclei. Eur J Neurosci 1:222-246.

Kaupp UB, Seifert R (2001) Molecular diversity of pacemaker ion channels. Annu Rev Physiol 63:235-257.

Ludwig A, Budde T, Stieber J, Moosmang S, Wahl C, Holthoff K, Langebartels A, Wotjak C, Munsch T, Zong X, Feil S, Feil R, Lancel M, Chien KR, Konnerth A, Pape HC, Biel M, Hofmann F (2003) Absence epilepsy and sinus dysrhythmia in mice lacking the pacemaker channel HCN2. EMBO J 22:216-224.

Lüthi A, McCormick DA (1998a) Periodicity of thalamic synchronized oscillations: the role of $\mathrm{Ca}^{2+}$-mediated upregulation of $\mathrm{I}_{\mathrm{h}}$. Neuron 20:553-563.

Lüthi A, McCormick DA (1998b) H-current: properties of a neuronal and network pacemaker. Neuron 21:9-12.

Lüthi A, McCormick DA (1999) Modulation of a pacemaker current through $\mathrm{Ca}^{2+}$-induced stimulation of cAMP production. Nat Neurosci 2:634-641.

Lüthi A, Bal T, McCormick DA (1998) Periodicity of thalamic spindle waves is abolished by ZD7288, a blocker of $\mathrm{I}_{\mathrm{h}}$. J Neurophysiol 79:3284-3289.

McCormick DA, Bal T (1997) Sleep and arousal: thalamocortical mechanisms. Annu Rev Neurosci 20:185-215.

McCormick DA, Pape H-C (1990) Noradrenergic and serotonergic modulation of a hyperpolarization-activated cation current in thalamic relay neurones. J Physiol (Lond) 431:319-342.

Meuth SG, Budde T, Kanyshkova T, Broicher T, Munsch T, Pape H-C (2003) Contribution of TWIK-related acid-sensitive $\mathrm{K}^{+}$channel 1 (TASK1) and TASK3 channels to the control of activity modes in thalamocortical neurons. J Neurosci 23:6460-6469.

Meuth SG, Kanyshkova T, Landgraf P, Pape HC, Budde T (2005) Influence of $\mathrm{Ca}^{2+}$-binding proteins and the cytoskeleton on $\mathrm{Ca}^{2+}$-dependent inactivation of high-voltage activated $\mathrm{Ca}^{2+}$ currents in thalamocortical relay neurons. Pflügers Arch 450:111-122. 
Moosmang S, Biel M, Hofmann F, Ludwig A (1999) Differential distribution of four hyperpolarization-activated cation channels in mouse brain. Biol Chem 380:975-980.

Much B, Wahl-Schott C, Zong X, Schneider A, Baumann L, Moosmang S, Ludwig A, Biel M (2003) Role of subunit heteromerization and $\mathrm{N}$-linked glycosylation in the formation of functional hyperpolarizationactivated cyclic nucleotide-gated channels. J Biol Chem 278:43781-43786.

Neher E (1992) Correction for liquid junction potentials in patch clamp experiments. Methods Enzymol 207:123-131.

Pape H-C (1992) Adenosine promotes burst activity in guinea-pig geniculocortical neurones through two different ionic mechanisms. J Physiol (Lond) 447:729-753.

Pape H-C (1996) Queer current and pacemaker: the hyperpolarizationactivated cation current in neurons. Annu Rev Physiol 58:299-327.

Pinault D, Leresche N, Charpier S, Deniau JM, Marescaux C, Vergnes M, Crunelli V (1998) Intracellular recordings in thalamic neurones during spontaneous spike and wave discharges in rats with absence epilepsy. J Physiol (Lond) 509:449-456.

Renier WO, Coenen AML (2000) Human absence epilepsy: the WAG/Rij rat as a model. Neurosci Res Com 26:181-191.

Robinson RB, Siegelbaum SA (2003) Hyperpolarization-activated cation currents: from molecules to physiological function. Annu Rev Physiol 65:453-480.

Santoro B, Baram TZ (2003) The multiple personalities of h-channels. Trends Neurosci 26:550-554.

Santoro B, Chen S, Luthi A, Pavlidis P, Shumyatsky GP, Tibbs GR, Siegelbaum SA (2000) Molecular and functional heterogeneity of hyperpolarization-activated pacemaker channels in the mouse CNS. J Neurosci 20:5264-5275.

Seidenbecher T, Pape HC (2001) Contribution of intralaminar thalamic nuclei to spike-and-wave-discharges during spontaneous seizures in a genetic rat model of absence epilepsy. Eur J Neurosci 13:1537-1546.

Seidenbecher T, Staak R, Pape H-C (1998) Relations between cortical and thalamic cellular activities during absence seizures in rats. Eur J Neurosci 10:1103-1112.
Shah MM, Anderson AE, Leung V, Lin X, Johnston D (2004) Seizureinduced plasticity of $\mathrm{h}$ channels in entorhinal cortical layer III pyramidal neurons. Neuron 44:495-508.

Sieg F, Obst K, Gorba T, Riederer B, Pape H-C, Wahle P (1998) Postnatal expression pattern of calcium-binding proteins in organotypic thalamic cultures and in the dorsal thalamus in vivo. Brain Res Dev Brain Res 110:83-95.

Staak R, Pape HC (2001) Contribution of $\mathrm{GABA}_{\mathrm{A}}$ and $\mathrm{GABA}_{\mathrm{B}}$ receptors to thalamic neuronal activity during spontaneous absence seizures in rats. J Neurosci 21:1378-1384.

Steriade M (2003) Neuronal substrates of sleep and epilepsy. Cambridge, UK: Cambridge UP.

Steriade M, Jones EG, McCormick DA (1997) Thalamus, Ed 1. Amsterdam: Elsevier.

Strauss U, Kole MH, Brauer AU, Pahnke J, Bajorat R, Rolfs A, Nitsch R, Deisz RA (2004) An impaired neocortical Ih is associated with enhanced excitability and absence epilepsy. Eur J Neurosci 19:3048-3058.

Trivedi B, Kramer RH (1998) Real-time patch-cram detection of intracellular cGMP reveals long-term suppression of responses to NO and muscarinic agonists. Neuron 21:895-906.

Ulens C, Tytgat J (2001a) Functional heteromerization of HCN1 and HCN2 pacemaker channels. J Biol Chem 276:6069-6072.

Ulens C, Tytgat J (2001b) Gi- and Gs-coupled receptors up-regulate the cAMP cascade to modulate $\mathrm{HCN} 2$, but not $\mathrm{HCN} 1$ pacemaker channels. Pflügers Arch 442:928-942.

Wang J, Chen S, Nolan MF, Siegelbaum SA (2002) Activity-dependent regulation of HCN pacemaker channels by cyclic AMP: signaling through dynamic allosteric coupling. Neuron 36:451-461.

Yu H, Wu J, Potapova I, Wymore RT, Holmes B, Zuckerman J, Pan Z, Wang H, Shi W, Robinson RB, El-Maghrabi MR, Benjamin W, Dixon J, McKinnon D, Cohen IS, Wymore R (2001) MinK-related peptide 1: a beta subunit for the HCN ion channel subunit family enhances expression and speeds activation. Circ Res 88:E84-E87.

Zaccolo M, De Giorgi F, Cho CY, Feng L, Knapp T, Negulescu PA, Taylor SS, Tsien RY, Pozzan T (2000) A genetically encoded, fluorescent indicator for cyclic AMP in living cells. Nat Cell Biol 2:25-29. 